\title{
Knowledge, awareness, attitudes and screening practices towards breast and cervical cancer among women in Nepal: a scoping review
}

\author{
Candice Rademaker ${ }^{1} \cdot$ Shital Bhandary ${ }^{2} \cdot$ Helena Harder $^{3}$ (1)
}

Received: 9 September 2021 / Accepted: 30 November 2021 / Published online: 22 December 2021

(c) The Author(s) 2021

\begin{abstract}
Aim Breast and cervical cancers have emerged as major global health challenges and disproportionately affect women in low- and middle-income countries, including Nepal. This scoping review aimed to map the knowledge, attitudes and screening practices for these cancers among Nepali women to improve cancer outcomes and reduce inequality.

Methods Five electronic databases (CINAHL, Embase, Global Health, PsycINFO and PubMed), grey literature, and reference and citation lists were searched for articles published in English up to June 2021. Articles were screened against inclusion/exclusion criteria, and data from eligible studies were extracted. Results were summarised narratively.

Results The search yielded 615 articles, 38 of which were included in this scoping review $(27$ cervical cancer, 10 breast cancer, 1 both cancers). Levels of knowledge regarding breast and cervical varied widely. The main knowledge gaps were misconceptions about symptoms and risk factors, and poor understanding of screening behaviours. Screening practices were mostly inadequate due to socio-cultural, geographical or financial barriers. Positive attitudes towards cervical screening were associated with higher education and increased knowledge of screening modalities. Higher levels of knowledge, (health) literacy and participation in awareness campaigns facilitated breast cancer screening.

Conclusion Knowledge and screening practices for breast and cervical cancer among Nepali women were poor and highlight the need for awareness and education programmes. Future research should explore community health worker-led awareness and screening interventions for cervical cancer, and programmes to increase the practice of breast self-examination and clinical breast examinations to support early diagnosis of breast cancer.
\end{abstract}

Keywords Breast cancer $\cdot$ Cervical cancer $\cdot$ Knowledge $\cdot$ Attitudes $\cdot$ Screening practices $\cdot$ Nepal

\section{Introduction}

Cancer is a growing global concern. According to the estimates published by GLOBOCAN, there were 19 million new cancer cases and almost 10 million cancer deaths worldwide in 2020 (Sung et al. 2021). The number of new cases is

Helena Harder

h.harder@sussex.ac.uk

1 Brighton and Sussex Medical School, University of Sussex, Brighton, UK

2 School of Public Health, Patan Academy of Health Sciences, Patan, Kathmandu, Nepal

3 Sussex Health Outcomes Research \& Education in Cancer (SHORE-C), Brighton and Sussex Medical School, University of Sussex, Brighton, UK projected to rise by $47 \%$ to over 28 million in 2040, with the greatest increases expected in low- and middle-income countries (LMICs) (Sung et al. 2021). This is attributed to population growth and increased exposure to risk factors such as smoking, dietary changes and physical inactivity. It is in keeping with the epidemiological transition which causes a shift in the disease burden from predominantly infectious diseases to non-communicable diseases (NCDs), including cancer (Rai 2018; Remais et al. 2013; Sung et al. 2021). Women in LMICs are disproportionately affected by cancer, and have a higher disease burden due to vulnerabilities related to gender inequality, poverty and environmental factors (Ginsburg et al. 2017). Breast cancer (BC) is the most commonly diagnosed cancer and cervical cancer (CC) the fourth most common cancer in women worldwide (Sung et al. 2021). Both cancers have emerged as two major health challenges for women in LMICs, as mortality rates 
are substantially higher for both cancers compared to rates in high-income countries (HICs) (Bray et al. 2012; Heer et al. 2020; Sung et al. 2021; Torre et al. 2017).

Many LMICs have inadequate capacity to provide accessible breast and cervical cancer screening and cancer care, including Nepal. Nepal is among the least developed countries in the world. Around $25 \%$ of its estimated population of approximately 30 million live below the poverty line (OECD 2021). The country has a hybrid healthcare system, with the public sector providing most of the healthcare, mainly in primary health centres, health posts or secondary care hospitals, and by deploying community health workers or volunteers (Gyawali et al. 2020; Rai et al. 2018). Nepal lacks universal health coverage, and the voluntary Social Health Security Programme which was introduced in 2013 is still unaffordable for many (Ghimire et al. 2019; Mishra et al. 2015). Out-of-pocket expenditure has remained the principal means of financing healthcare, including cancer treatment, but this often leads to catastrophic health expenditure (Khatiwoda et al. 2019; Mishra et al. 2015; WHO 2017). Effective cancer control is therefore key in reducing health inequalities in Nepal.

Monitoring epidemiological trends in cancer through population-based cancer registries (PBCR) is important for cancer control, as it allows for the evaluation of the effectiveness of cancer screening programmes and the assessment of inequalities in cancer treatment, and supports the planning of cancer care services (Parkin 2008). In 2018, PBCR was introduced in Nepal in some districts, and although it was recently expanded, it still covers only $20 \%$ of the population (Gyawali et al. 2020; Subedi et al. 2020, 2021). The lack of a robust PBCR hinders not only the ability to assess cancer incidence and the impact of cancer in the country, but also makes the development of cancer management initiatives more difficult.

Health or cancer literacy also plays an important role in cancer control and prevention (Brand et al. 2019; Koirala et al. 2021; Oldach and Katz 2014). Increasing awareness of cancer risk factors can enhance cancer screening behaviours and cancer preventative practice, reduce the number of late presentations, and will help to remove the socio-cultural barriers to cancer care (Gyawali et al. 2020; Musa et al. 2017; Sentell et al. 2015). Additionally, determining levels of awareness about cancer and cancer risk factors is key to support the development and implementation of evidencebased intervention and/or screening programmes to curb the future burden of breast and cervical cancer in LMICs.

A previous review of CC screening practices and barriers in Nepal showed shortfalls in methodology (Kafle and Panth 2017), whereas a meta-analysis about BC awareness focused only on breast self-examination (BSE) (Sathian et al. 2019). Given the importance of $B C$ and $C C$ awareness and attitudes towards screening, a scoping review was conducted. A scoping review is a useful method where the aim is to understand and summarize the extent of research in a given area where data are varied and/or heterogeneous. The objectives of this review were to examine and map the levels of knowledge of BC and CC among Nepali women, to determine the use of screening practices for these cancers, and to assess women's attitudes towards these practices. The findings will contribute to a better understanding and could help lay the groundwork for the design of interventions and strategies to improve cancer outcomes and reduce inequalities for women in Nepal.

\section{Methods}

\section{Review approach}

This scoping review was conducted in accordance with relevant methodological guidance (Peters et al. 2015a, b), and the results were reported using the Preferred Reporting Items for Systematic Reviews and Meta-Analyses extension for scoping reviews (PRISMA-ScR) guidelines (Tricco et al. 2018). A completed checklist can be found in the online Supplementary Information. A review protocol was developed and can be accessed upon request.

\section{Search strategy and information sources}

An initial limited search was performed to identify the primary search terms (e.g. analysis of the text words contained in the title and abstract, and index terms). The search strategy was developed with guidance from a health science subject librarian and pre-tested prior to the actual search. The following search terms and keywords were used: (Nepal*) AND (breast OR mammary OR cervi* OR uterine) AND (cancer* OR neoplasm* OR tumour* OR tumor* OR carcinoma OR malignan* OR colposcopy OR human papillomavirus OR HPV DNA OR PAP smear OR Pap smear test OR Papanicolaou OR direct visualisation OR liquid cytology OR visual inspection).

Five electronic databases (PsycINFO, PubMed, Global Health, Embase and CINAHL) were systemically searched for relevant studies published in English. No date restrictions were imposed, and citations published up to June 2021 were included. A grey literature search was undertaken (i.e. Google Scholar), and references and citations of eligible studies were reviewed (snowball sampling) for additional studies and reports of relevance. Studies were excluded if they were reviews, editorials or study protocols, or if data for female participants could not be disaggregated from the results. No further limits were placed on study design, in order to capture information from a wide range of sources and to determine the extent, range and nature of available 
research on the topic. Table 1 shows a summary of the population, interest and context (PICo) inclusion and exclusion criteria for this scoping review.

\section{Study selection}

Articles identified from the final search of the databases were collated using Mendeley Reference Manager software, and duplicates were removed. Articles were primarily screened by their title and abstract by a reviewer (CR), tracking reasons for exclusions, and reviewed by a second researcher $(\mathrm{HH})$. Following this initial screening process, further screening was conducted by reading the full articles and applying the criteria set out in Table 1 . Three reviewers independently screened the data; disagreements were resolved through discussion, and decisions were tracked using an Excel spreadsheet.

\section{Data extraction and charting}

Data were extracted from the full texts by a single researcher (CR). A second researcher (HH) independently reviewed and extracted the data, testing validity. Differences in data extraction were resolved by discussion.

Data were obtained on study details (year published, country of origin, study purpose and methodology), population characteristics (setting, age, marital status and education/literacy levels), and main study outcomes. Data were charted regarding knowledge, practices and attitudes towards $\mathrm{BC}$ and $\mathrm{CC}$. This included a quantitative/qualitative synthesis: the percentage that had heard of $\mathrm{BC} / \mathrm{CC}$, levels of knowledge of $\mathrm{BC} / \mathrm{CC}$ (including risk factors, common symptoms and treatment options), attitudes towards the cancers or screening for the cancers (including barriers to/facilitators of screening or treatment), sources of information, and factors associated with knowledge and attitudes.

\section{Quality assessment}

A quality assessment was not conducted, which is consistent with guidance on scoping review conduct (Peters et al. 2015a, b).

\section{Results}

\section{Search results}

Figure 1 shows the PRISMA diagram of the process used in paper selection. The search returned 687 citations. After duplicates were removed, 615 were screened via their titles and abstract. The full texts of 58 citations were obtained for further review. Twenty studies were excluded; reasons outlining the exclusion of these studies are displayed in Fig. 1. A total of 38 articles were included in this scoping review. All studies were published between 2001 and 2021, and nearly half (45\%) within the last 5 years. Twenty-seven (71\%) studies focused on CC (Baral et al. 2020; Bhatta et al. 2020; Darj et al. 2019; Ghimire and Pathak 2020; Andersen et al. 2020; Gyenwali et al. 2013; Johnson et al. 2014; Joy et al. 2011; Khadka et al. 2017; Maharjan et al. 2020; Pandey and Karmacharya 2017; Poudel and Sumi 2019; Rachana and Giri 2019; Ranabhat et al. 2014; Ranjit et al. 2016; Satyal 2013; Shakya et al. 2016; Sherpa 2007; Sherpa et al. 2020; Shrestha et al. 2013; Shrestha 2014; Shrestha and Dhakal 2017; Shrestha 2017; Shrestha et al. 2020; Shrestha et al. 2021a; Thapa 2018; Thapa et al. 2018;). Ten studies (26\%) concerned BC (Bhandari et al. 2016; Bhandari et al. 2021; Bhatt et al. 2011; Braun and Itano 2011; Gupta et al. 2015; Narasingrao et al. 2013; Parajuli and Mandal 2010; Sathian et al. 2014; Shrestha 2012; Shrestha et al. 2017). One study evaluated knowledge, attitude and screening practice for both cancers (Shah et al. 2010).

Most studies had a cross-sectional quantitative design; three studies were qualitative and used focus groups or indepth interviews (Darj et al. 2019; Andersen et al. 2020; Shrestha et al. 2020). One case report (Braun and Itano 2011) and one conference abstract (Shrestha 2017) were included in the review. Four studies were not published in peer-reviewed journals: two master's dissertations (Sherpa 2007; Shrestha 2014), one PhD thesis (Satyal 2013) and one government research report (Shah et al. 2010). Sample sizes ranged from 1 to 1420 . A total of 12,844 women were included in CC studies and 3268 in BC studies. While not all studies specified, both urban and rural settings were represented. The mean age of participants ranged from 17
Table 1 Population, Interest and Context (PICo) based inclusion and exclusion criteria

\begin{tabular}{lll}
\hline & Included & Excluded \\
\hline Problem & $\bullet$ Breast and cervical cancer & - Articles relating to other cancers \\
Population & $\bullet$ Women, of all ages, living in all areas & - Populations outside of Nepal \\
& of Nepal & - Studies including Nepali migrants \\
Interest & $\bullet$ Knowledge/awareness & $\bullet$ The biochemistry or pathological \\
& - Attitudes & subtypes of breast or cervical cancer \\
& $\bullet$ Screening practice/behaviours & in Nepal \\
Context & $\bullet$ Nepal & $\bullet$ Countries outside of Nepal \\
\hline
\end{tabular}


Fig. 1 Flowchart of study identification and selection
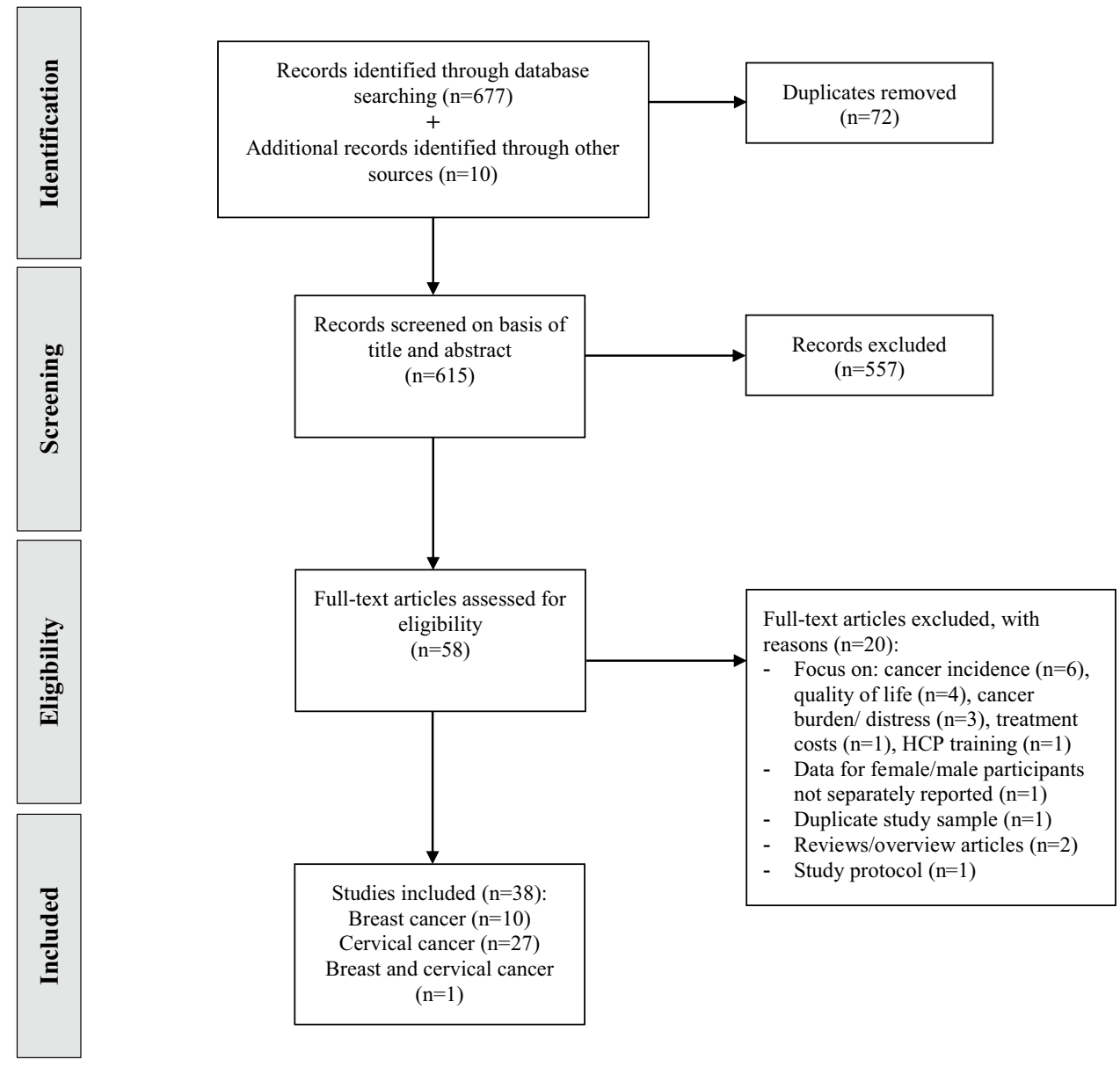

tudies included $(\mathrm{n}=38)$ :

Breast cancer $(\mathrm{n}=10)$

Cervical cancer $(\mathrm{n}=27)$

Breast and cervical cancer $(\mathrm{n}=1)$ to 53 years. Levels of illiteracy were reported in 21 studies $(53 \%)$ and ranged from $4 \%$ (Narasingrao et al. 2013) to $66 \%$ (Gyenwali et al. 2013). Study participants included students, housewives, mothers of high school students, teachers, nurses, visitors to health clinics, gynaecological in- and outpatients, and CC survivors. The majority of studies used researcher- or clinician-administered (semi-)structured surveys $(n=25,66 \%)$ in face-to-face interviews, or self-administered surveys $(n=8,21 \%)$. Ten studies reported knowledge or awareness scores, predominantly focusing on CC (Bhatt et al. 2011; Baral et al. 2020; Darj et al. 2019; Ghimire and Pathak 2020; Khadka et al. 2017; Poudel and Sumi 2019; Rachana and Giri 2019; Shrestha et al. 2013; Shah et al. 2010; Shrestha and Dhakal 2017). A review of medical records was carried out in one study (Shrestha 2014), and two studies offered women a Papanicolaou or Pap smear test (Ranabhat et al. 2014; Sherpa 2007).

\section{Breast cancer results}

General knowledge of breast cancer and symptoms The main characteristics of the selected BC studies $(n=11)$ are shown in Table 2. Knowledge of BC and its main symptoms varied widely. Shrestha (2012) found that only 30\% of hospital outpatients had heard of BC. The percentage of women who correctly identified a breast lump as the main presentation of BC ranged from 5\% (Sathian et al. 2014) to 78\% (Shrestha et al. 2017). Bhatt et al. (2011) noted that among 100 gynaecological inpatients, $89 \%$ knew that BC usually presents as a lump; however, $61 \%$ did not know that it can be painless. In contrast, Shrestha (2012) found that $61 \%$ knew that a painless lump and $100 \%$ that an axillary lump could be a sign of BC. Shrestha (2017) noted that $82 \%$ knew that BC can be a painless abnormal growth in the breast. Conversely, a study conducted on 1420 women and students in urban and rural regions of Pokhara valley found that just 5\% were aware that a breast lump is a warning sign for BC (Sathian et al. 2014). A study among healthcare professionals (HCPs) by Shah et al. (2010) showed that $84 \%$ of nurses and midwives were aware of BC signs and symptoms. Bhatt et al. (2011) found that mean knowledge scores of study participants was $65 \%$, and scores were higher among highly educated women, professionals and women counselled during medical visits. Common sources for BC information were television and radio (Shrestha 2012; Bhandari et al. 2016). 


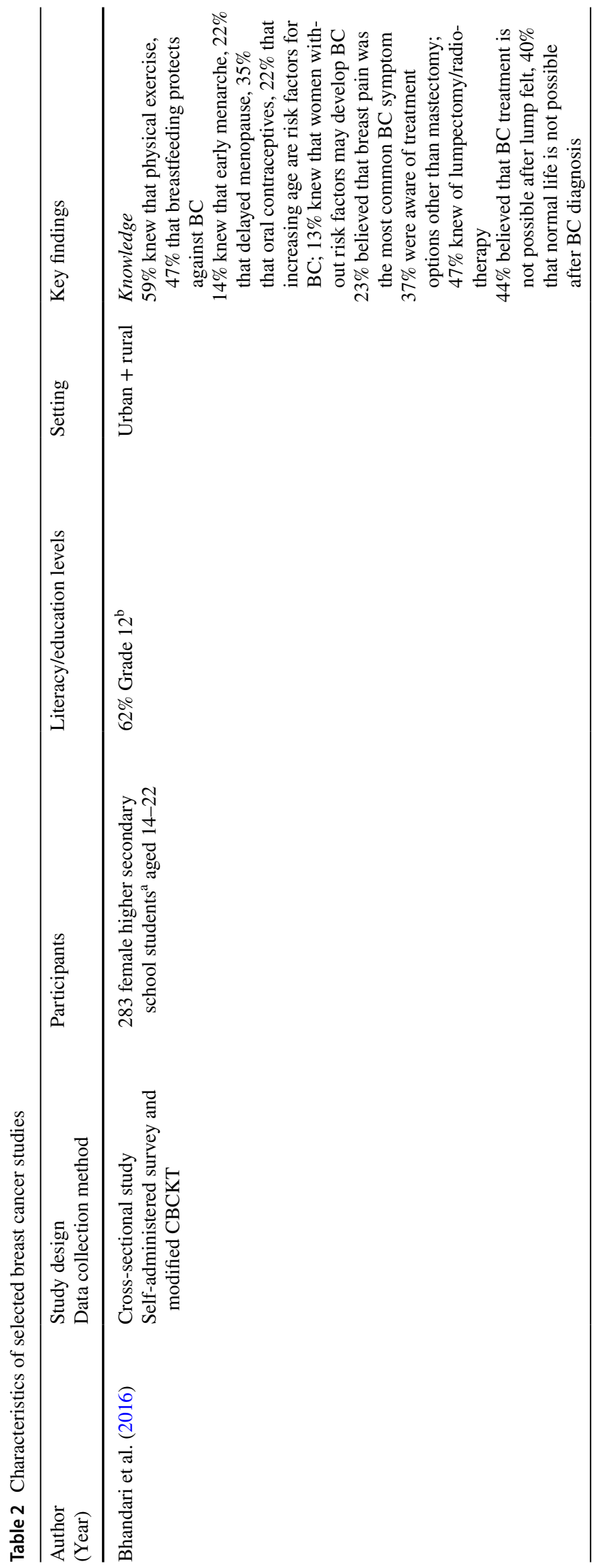




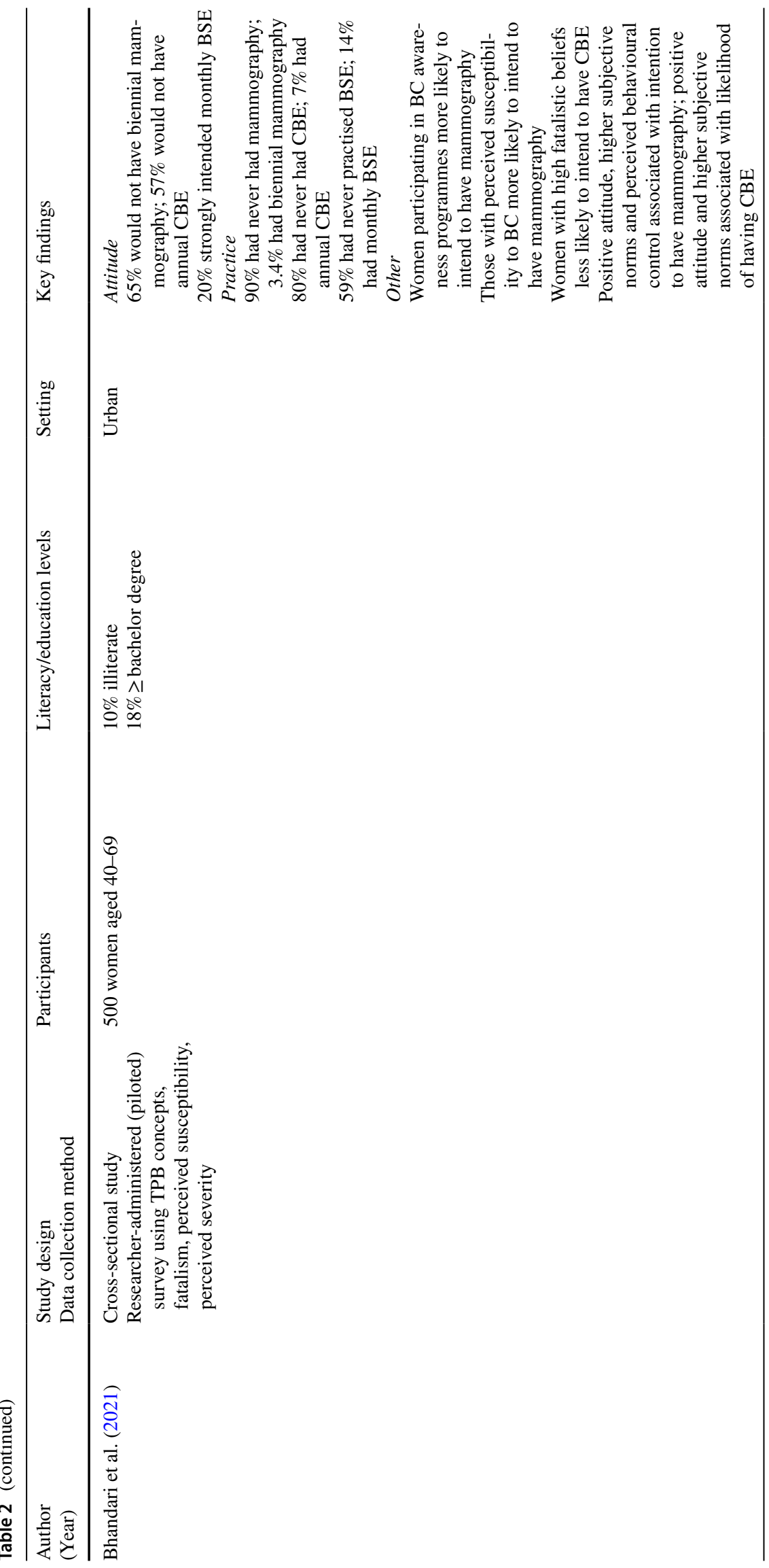




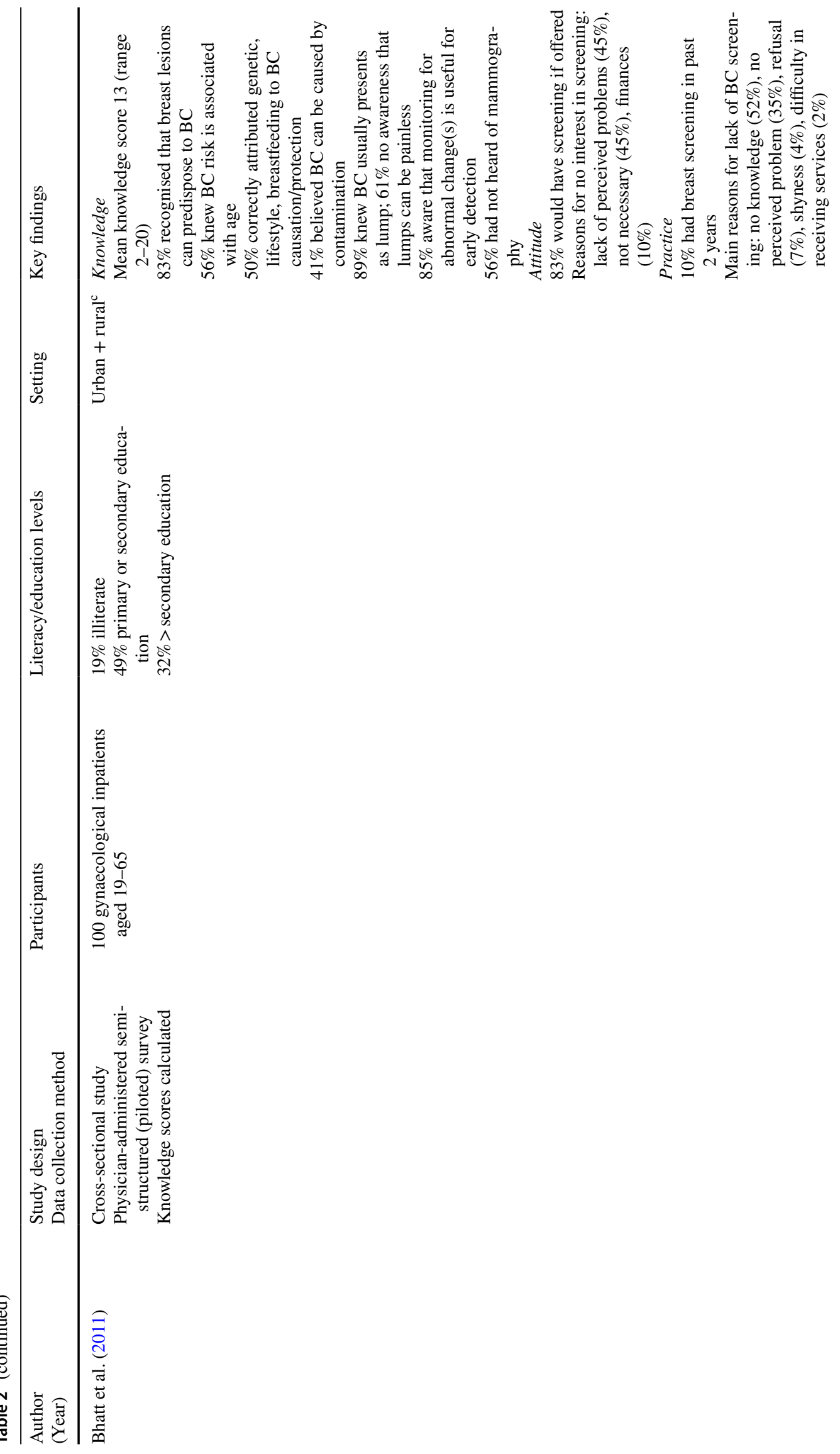




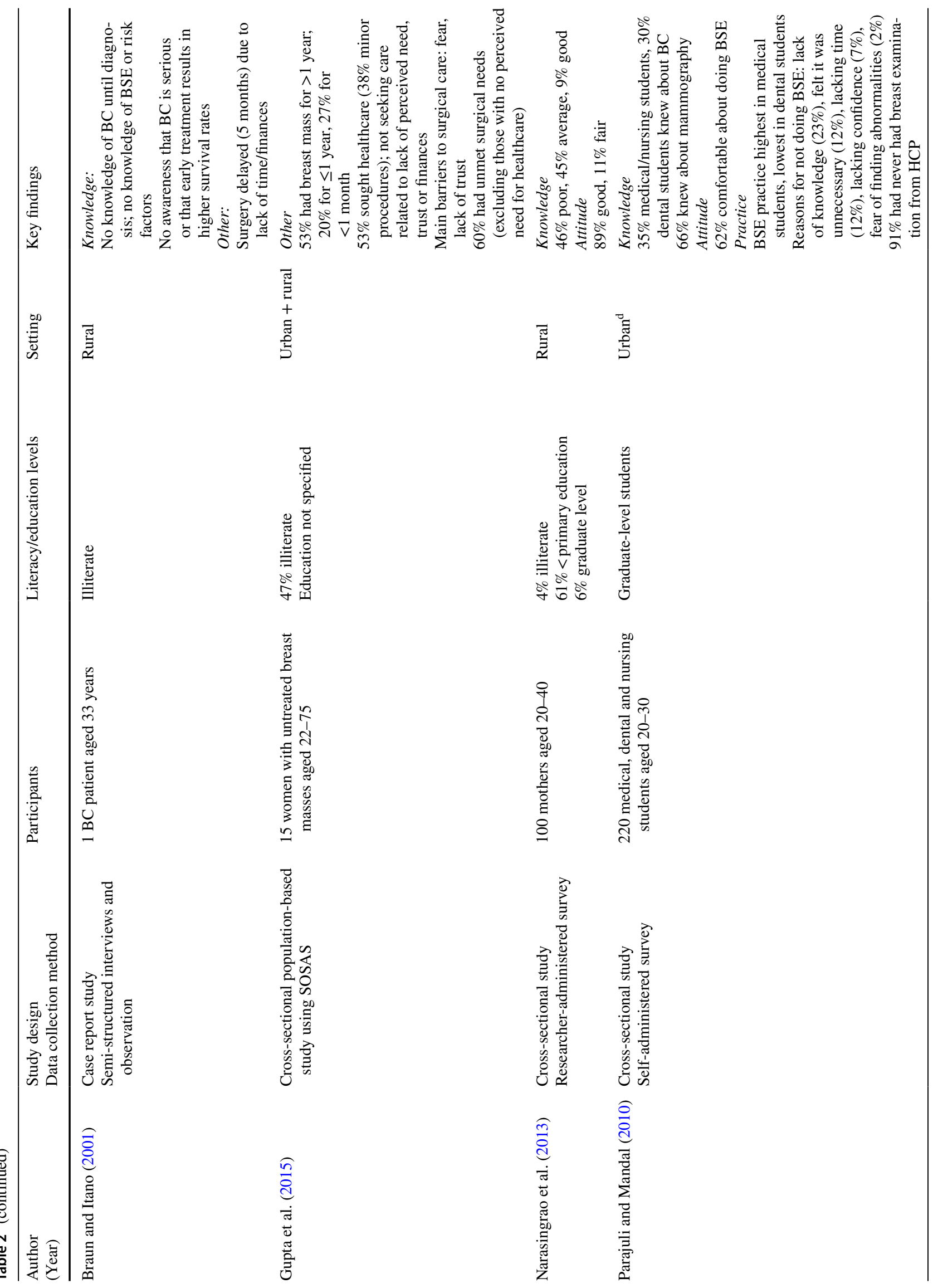




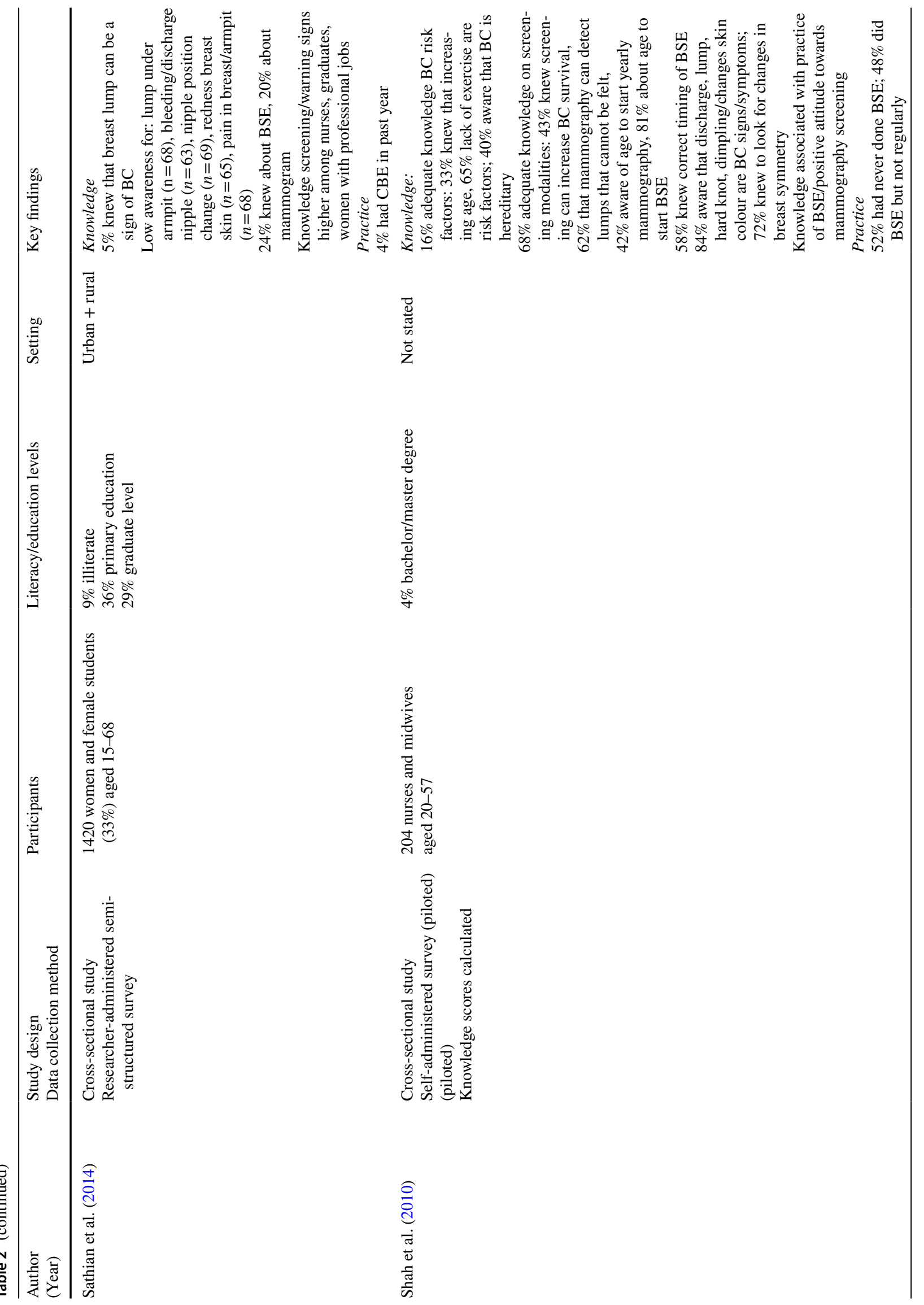




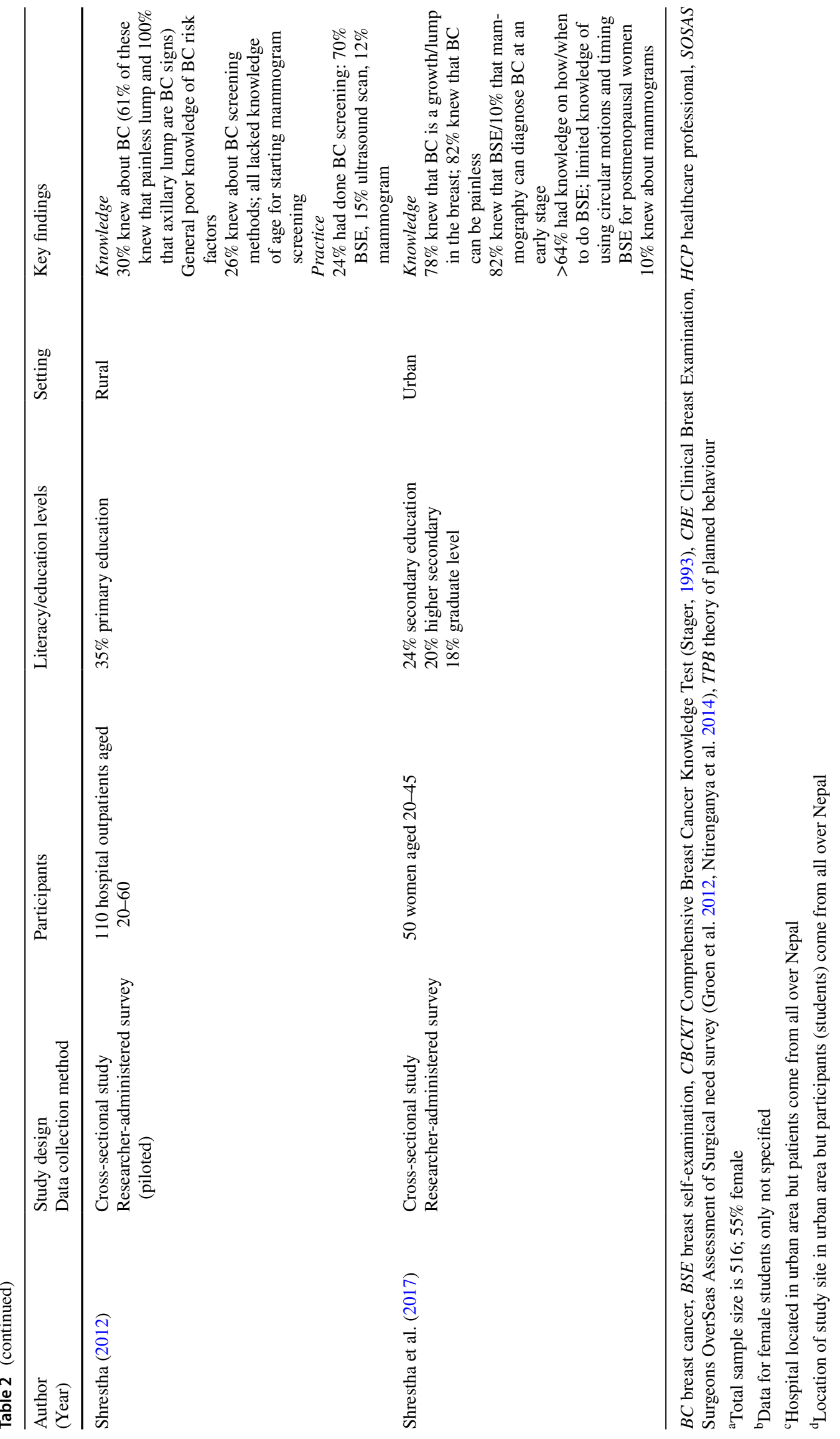


Knowledge of breast cancer risk factors A common theme in Table 2 is that knowledge of BC risk factors is poor. Bhandari et al. (2016) surveyed 283 female secondary students and found that $14 \%$ knew that early menarche, $22 \%$ that delayed menopause, and 35\% that the use of oral contraceptives are risk factors. Of the women Bhatt et al. (2011) included in their study, 56\% knew that BC is more common in older people; however, $41 \%$ incorrectly believed that contamination can cause BC. Shah et al. (2010) noted that 33\% knew that increasing age and $65 \%$ that lack of exercise are risk factors. Furthermore, $40 \%$ were aware that BC can be hereditary. Shrestha (2012) reported that general knowledge of $\mathrm{BC}$ risk factors was poor among participants.

Knowledge and practice of breast cancer screening Breast self-examination (BSE) was mentioned in seven studies (Bhandari et al. 2021; Shrestha et al. 2017; Sathian et al. 2014; Shrestha 2012; Parajuli and Mandal 2010; Braun and Itano 2011; Shah et al. 2010). Shrestha et al. (2017) found that of 50 reproductive-aged women from an urban area, $82 \%$ knew that BSE can lead to an early BC diagnosis, whereas in a study conducted with 1420 women in Pokhara valley, only $24 \%$ had heard of BSE.

Bhandari et al. (2021) reported on attitudes and practice towards BSE: 59\% never practised BSE, $14 \%$ had monthly BSE and $20 \%$ strongly intended to do monthly BSE. Practice of BSE varied in other studies; Shah et al. (2010) reported that $48 \%$ were performing BSE but not regularly. In contrast, Shrestha (2012) reported that $70 \%$ were practising regular BSE; however, there was limited knowledge on the use of circular motions and timing of BSE for postmenopausal women.

Higher rates of BSE practice were seen in medical students (compared to dental/nursing students) and those with more knowledge of risk factors and $\mathrm{BC}$ screening modalities for BC (Parajuli and Mandal 2010; Shah et al. 2010). Reasons cited for not practicing BSE other than lack of knowledge included not believing BSE to be necessary, lack of time, lack of confidence and fear of finding abnormalities (Parajuli and Mandal 2010). The most common sources for BSE information were HCPs $(60 \%)$ or media $(36 \%)$ (Shrestha et al. 2017).

Seven studies mentioned mammography; five included urban women (Bhandari et al. 2021; Shrestha et al. 2017; Shrestha 2012, Bhatt et al. 2011; Parajuli and Mandal 2010), one included rural and urban women (Sathian et al. 2014), and one did not specify the population (Shah et al. 2010). Sathian et al. (2014) reported that $20 \%$ had heard of mammography, Bhatt et al. (2011) found it to be $44 \%$ and Parajuli and Mandal (2010), 66\%. Shrestha et al. (2017) found that $10 \%$ knew that mammography aids early diagnosis of BC; however, most had no awareness that mammograms can be used for BC screening. Shah et al. (2010) noted that $62 \%$ knew mammography can detect lumps that cannot be felt, and $42 \%$ knew that yearly mammography is recommended to women aged 50 and over. Sathian et al. (2014) showed that knowledge of mammography was better in nurses, graduates and professionals compared to women from lower educational backgrounds (Sathian et al.; 2014).

Four studies reported on the uptake of mammography. Studies conducted by Bhandari et al. (2021), Shrestha (2012) and Bhatt et al. (2011) were based in urban areas and found uptake of mammography to be $10 \%$ (3.4\% biennial mammography), $2.7 \%$ and $2.3 \%$, respectively. The population was mixed rural and urban in the study conducted by Shah et al. (2010), and here just $1 \%$ had undergone mammography. Reasons for never having been screened for BC included lack of knowledge (52\%), no perceived problem $(35 \%)$, refusal $(7 \%)$, shyness $(4 \%)$ or difficulty in receiving services (2\%) (Bhatt et al. 2011). Bhatt et al. (2011) found that knowledge of mammography was significantly related to education and counselling done during medical visits. This was confirmed in a recent study by Bhandari et al. (2021), where women who had attended BC awareness programmes were more likely to intend to have a mammogram. This study also found that positive attitude, higher subjective norms and perceived susceptibility to BC were associated with the intention to undergo mammography.

Only one study mentioned clinical breast examination (CBE) (Bhandari et al. 2021). In an urban population of 500 women aged $40-69$ years, only $20 \%$ were familiar with $\mathrm{CBE}$ and $7 \%$ had annual CBE; $57 \%$ had a negative attitude towards CBE, most of whom were women with high fatalistic beliefs.

Impact of poor knowledge on screening behaviours Poor knowledge about BC impacts treatment-seeking behaviours. Gupta et al. (2015) noted in a study using a population-based survey of surgical needs that $33 \%$ did not receive surgical care for BC. Reasons cited were believing there to be no need for surgery, fear or lack of trust, and not having the financial assets for surgical care. Braun and Itano (2001) presented a case report of a 33-year-old woman with BC who delayed surgery by 5 months. This was due to multiple factors, including inability to pay for surgery or to take time away from household duties, lack of awareness of the seriousness of $\mathrm{BC}$, and not understanding that earlier treatment would improve prognosis. The patient did not know what $\mathrm{BC}$ was prior to diagnosis and lacked knowledge of $\mathrm{BC}$ risk factors and BSE.

\section{Cervical cancer results}

General knowledge of cervical cancer and symptoms Table 3 presents an overview of the 28 papers exploring knowledge, 


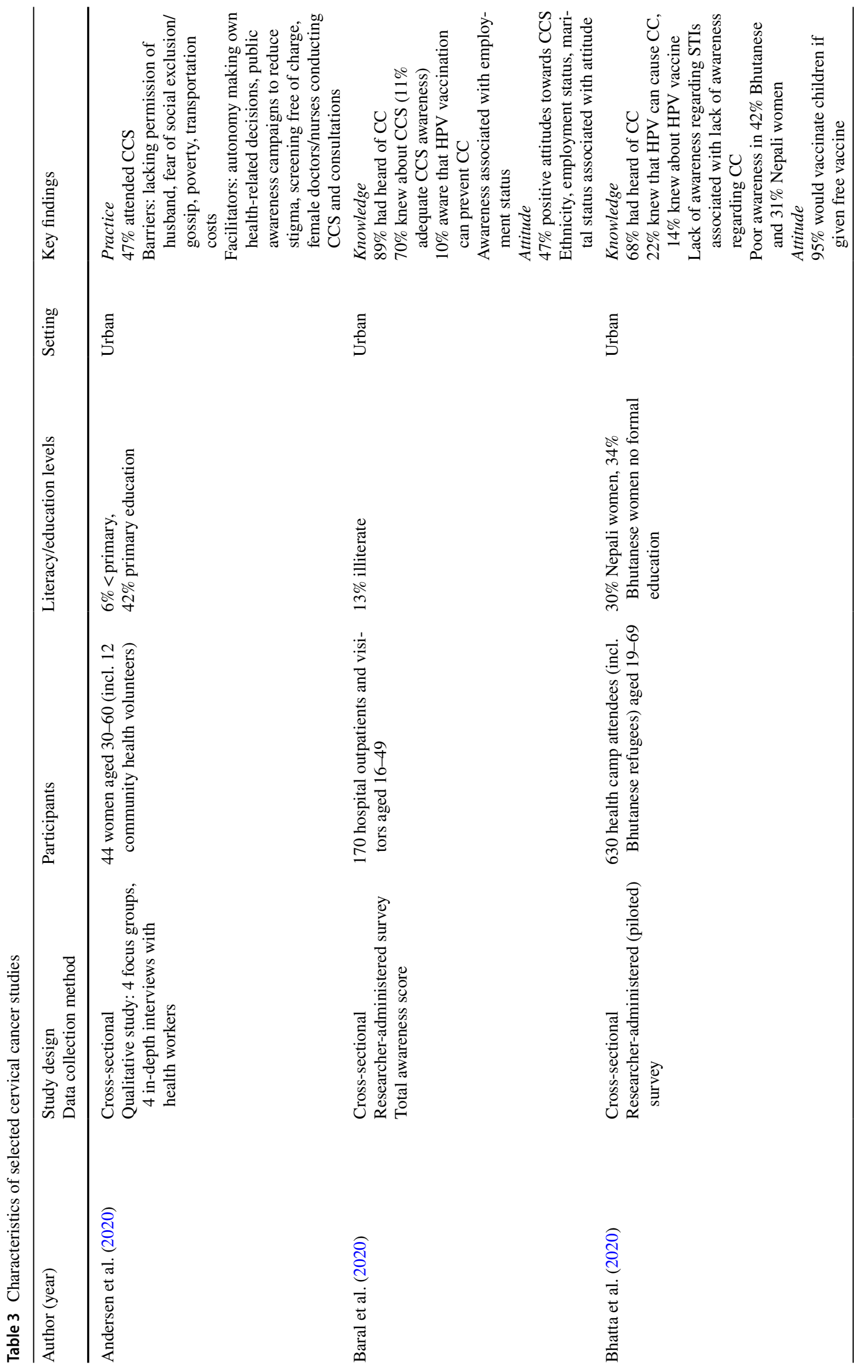




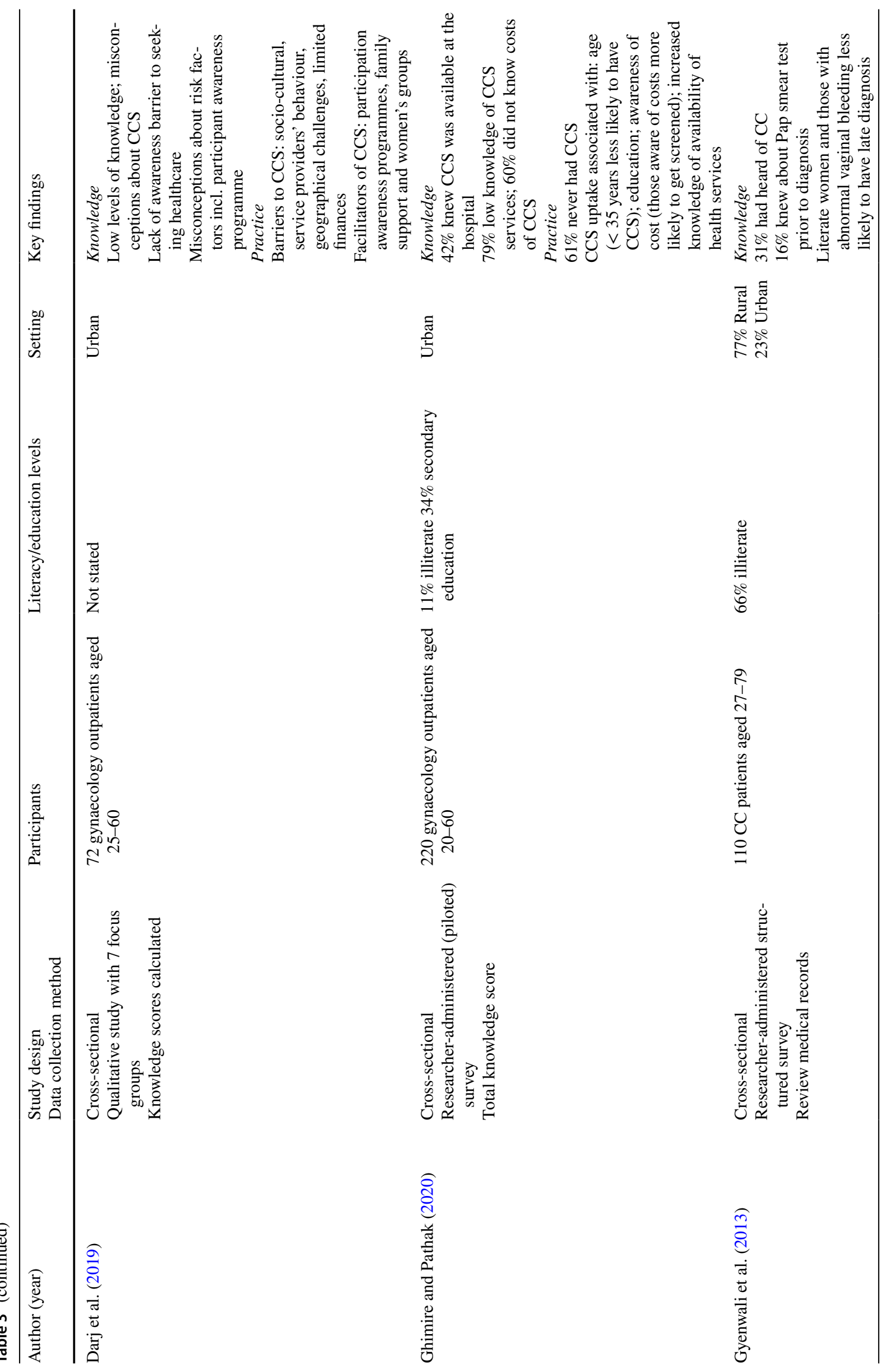




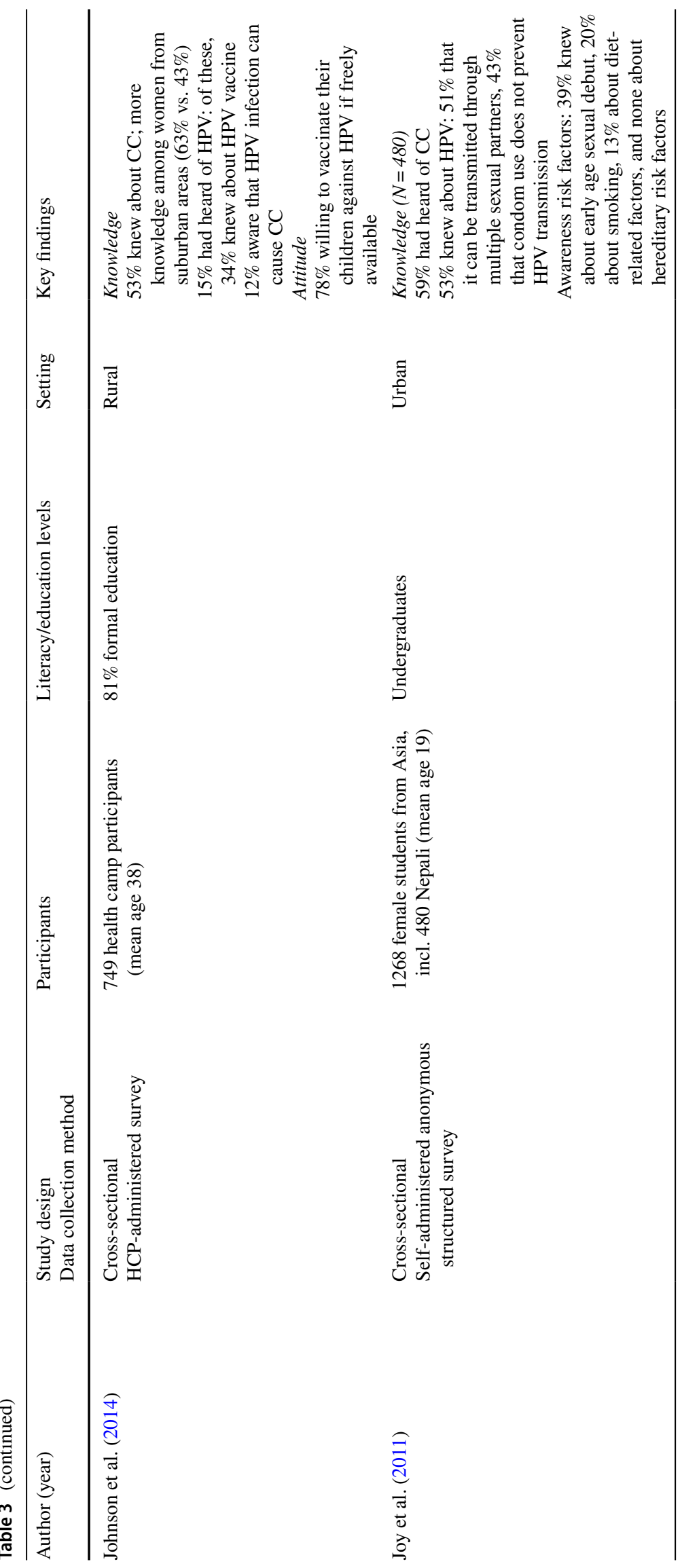




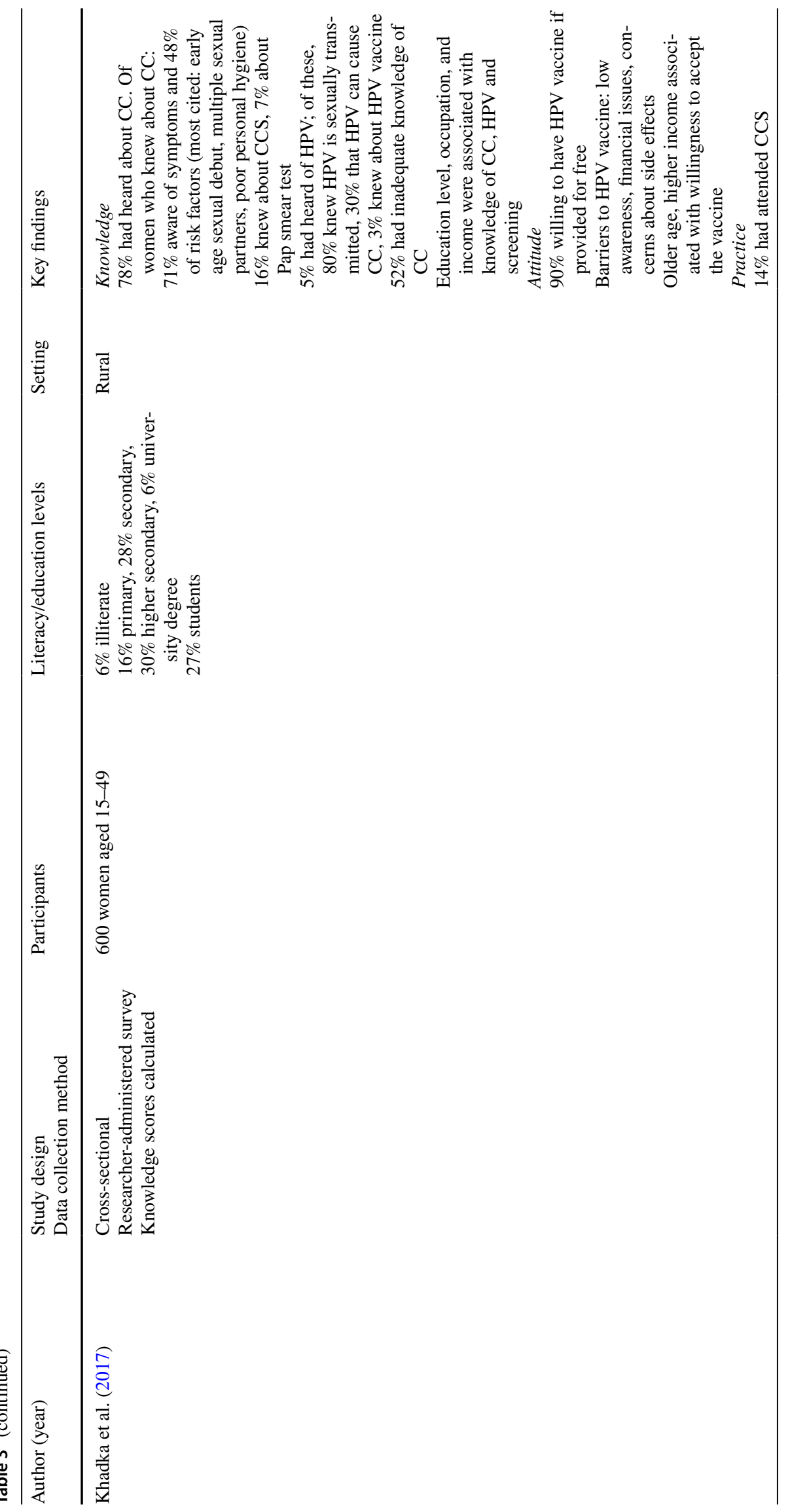




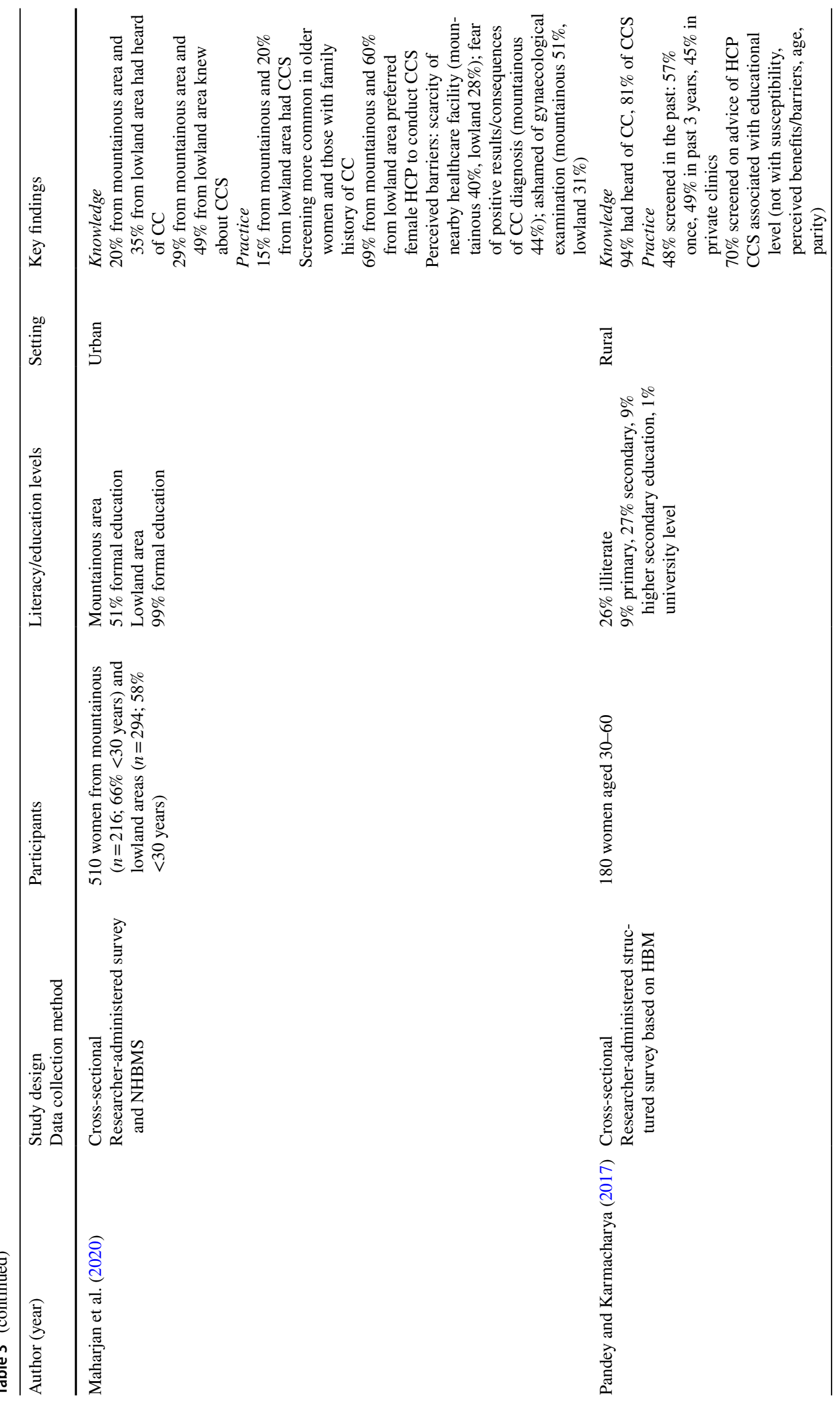




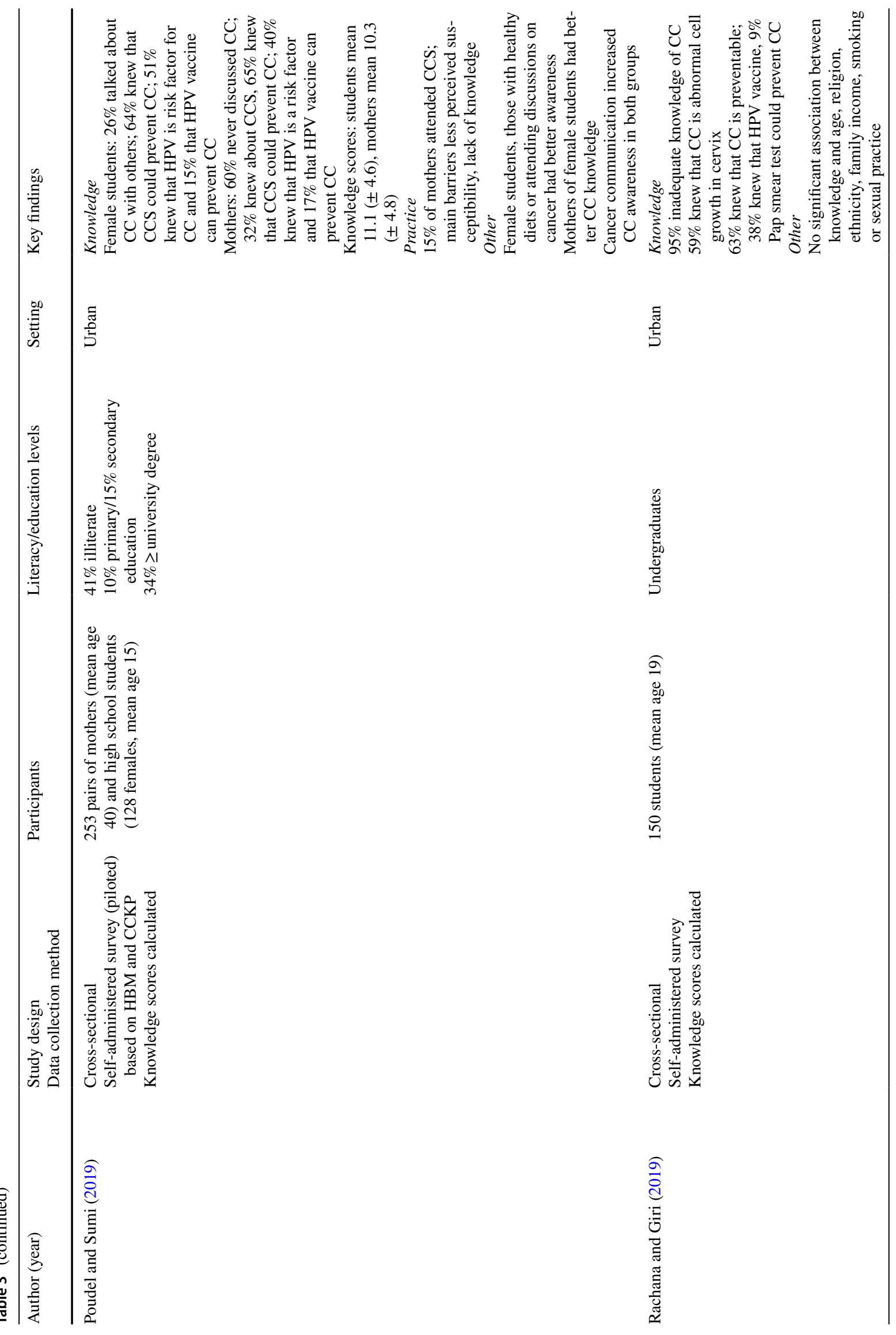




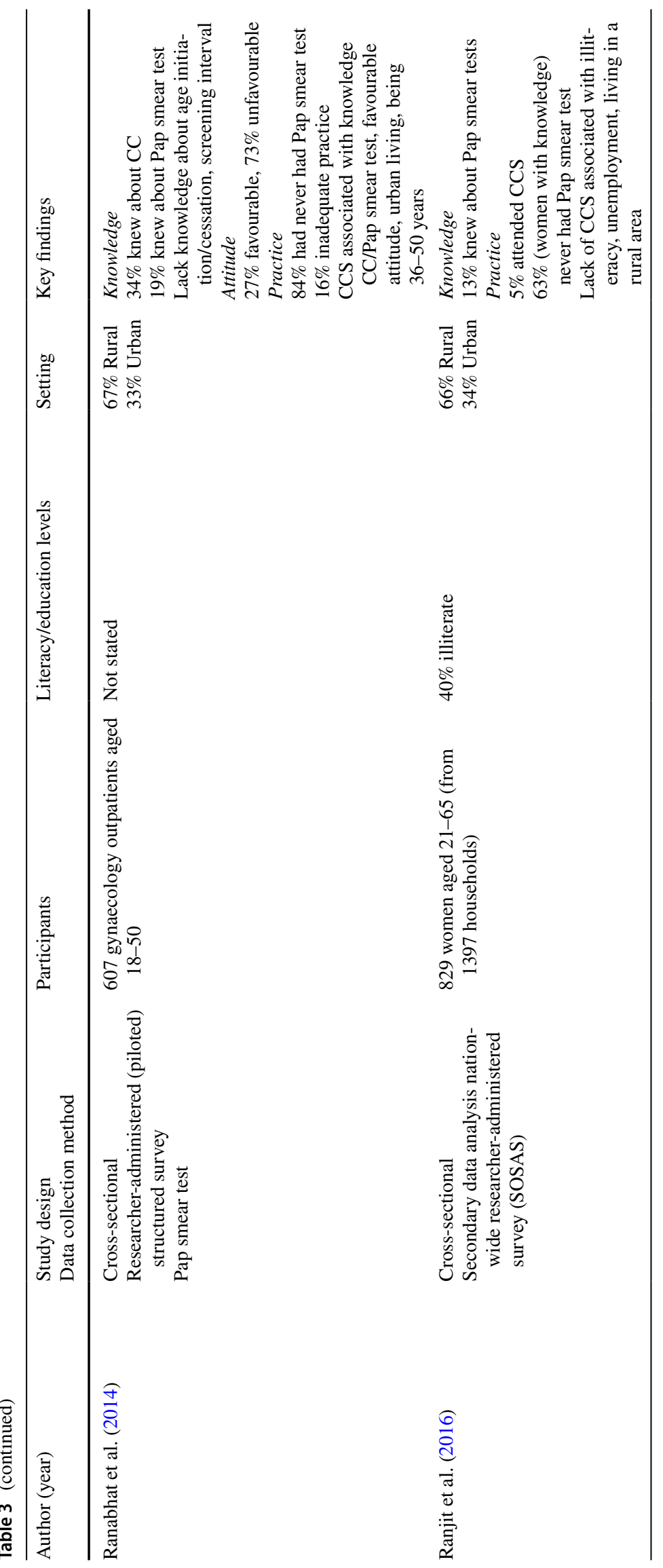


Journal of Public Health (2022) 30:1995-2027

2013

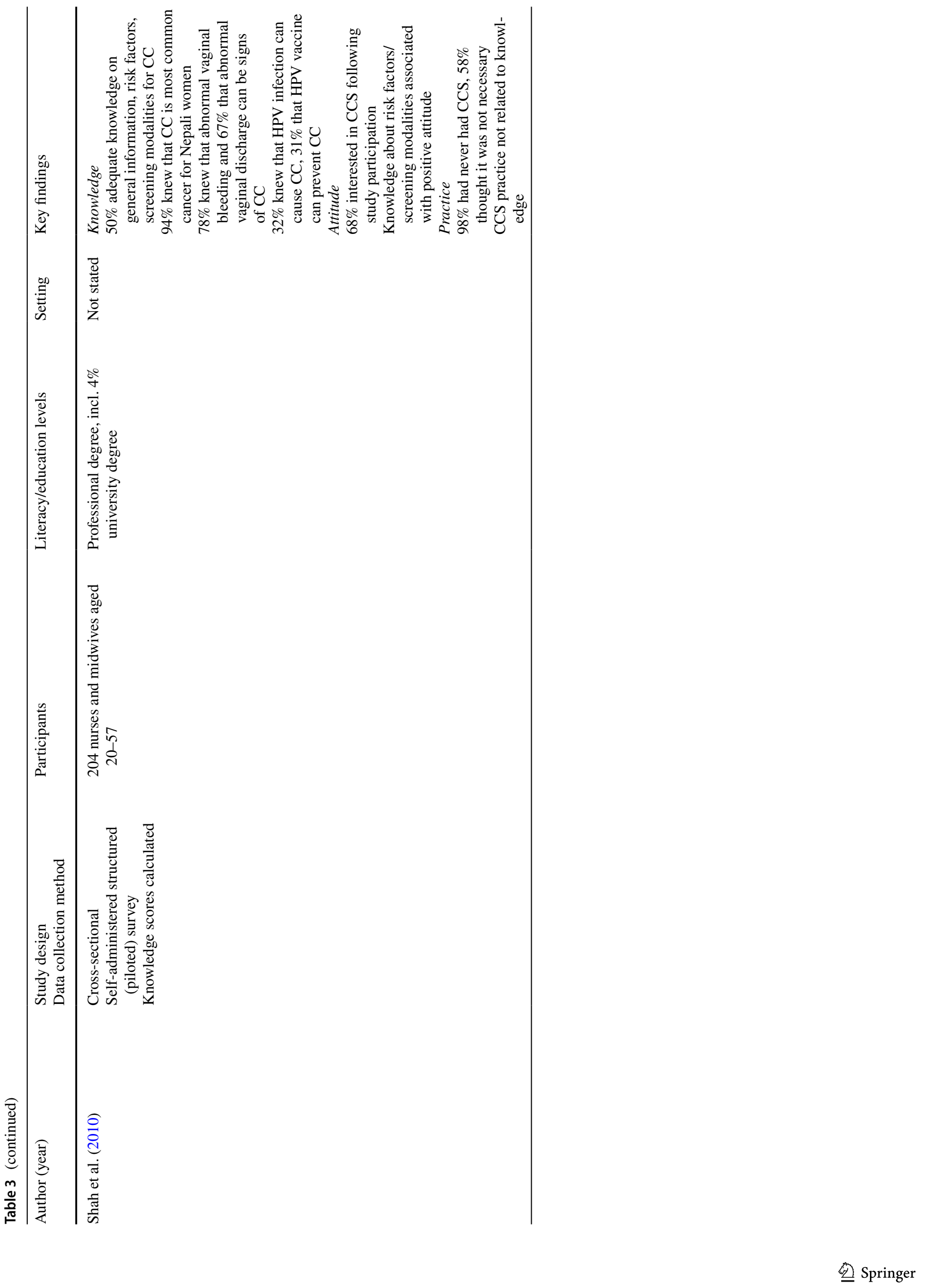




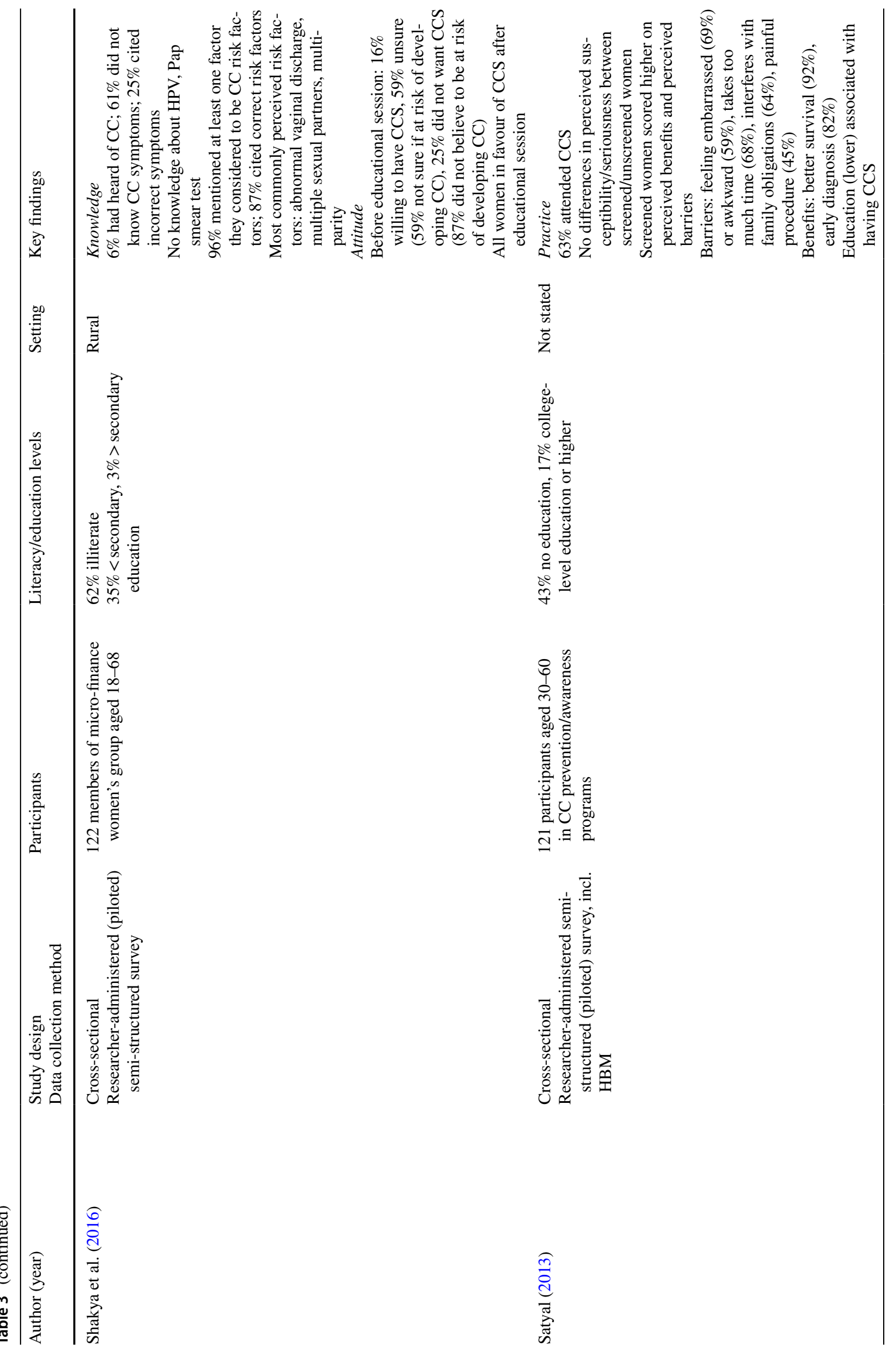




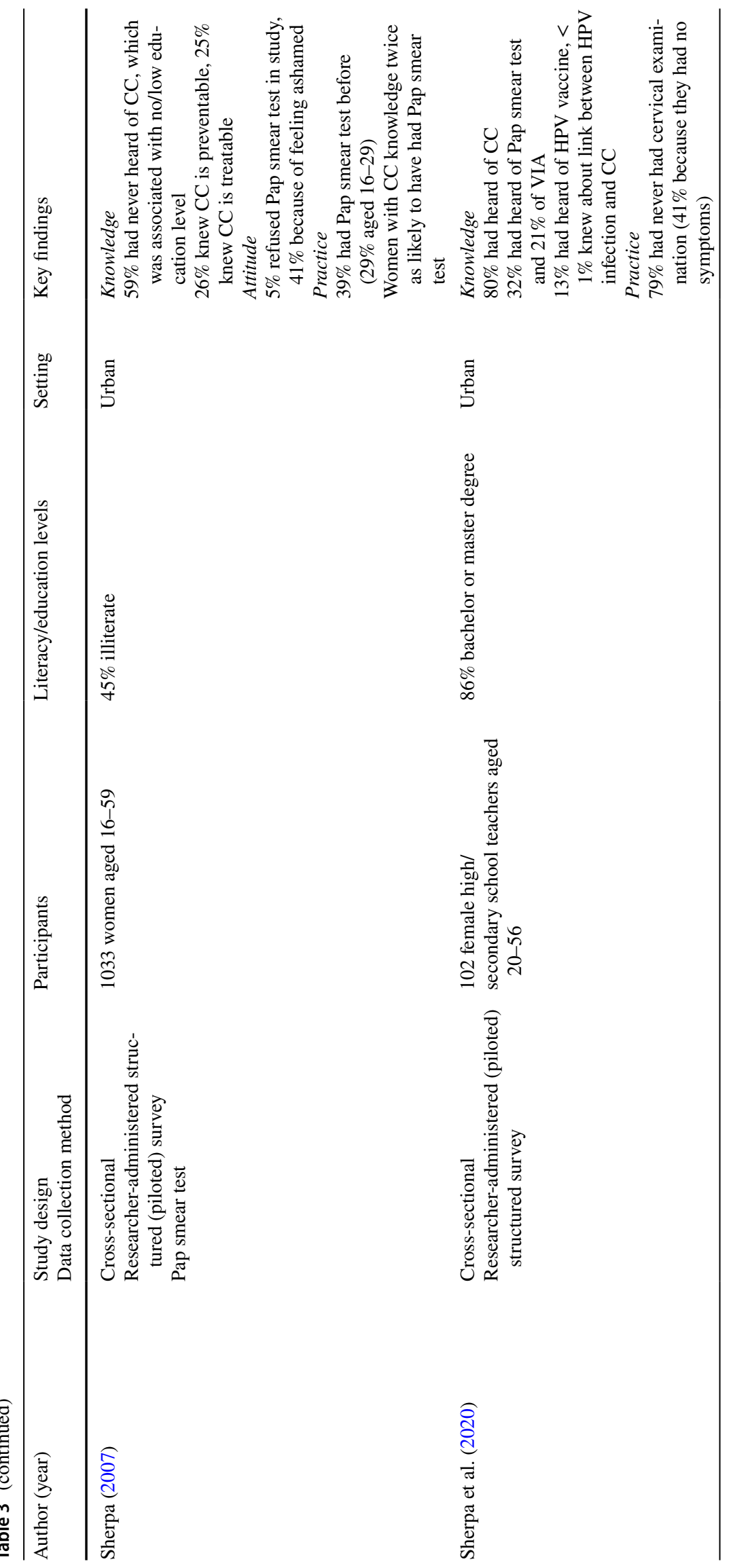




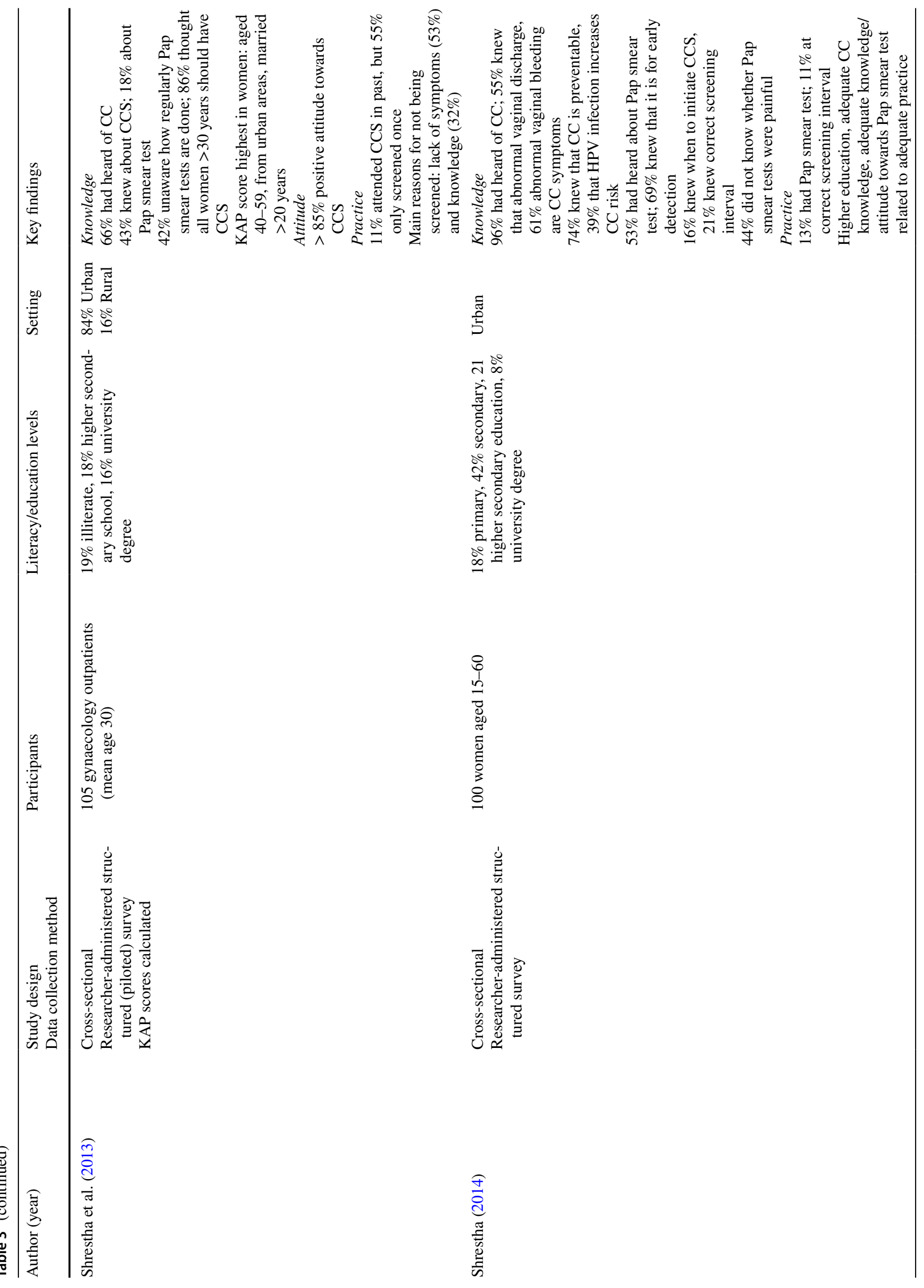




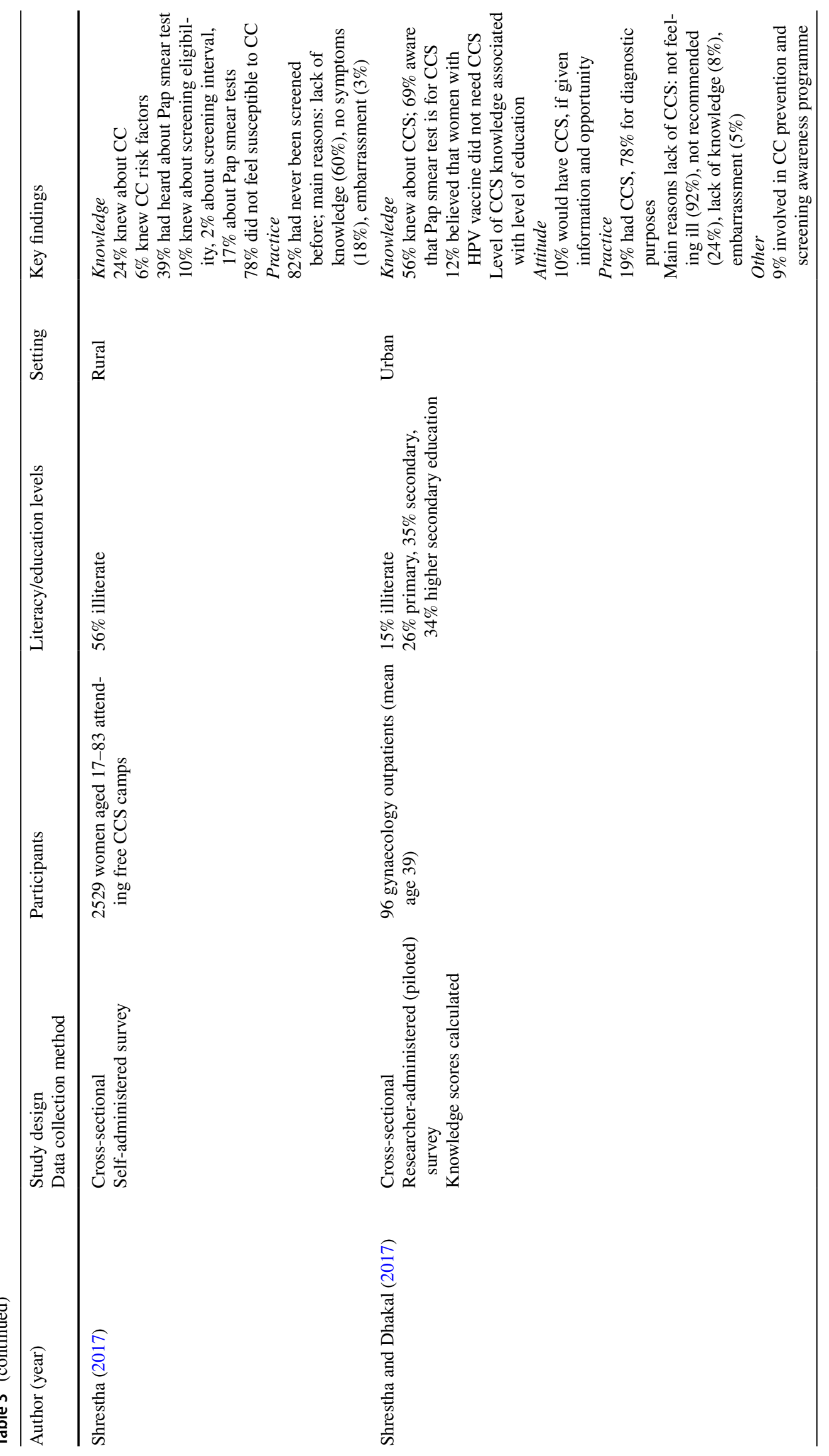




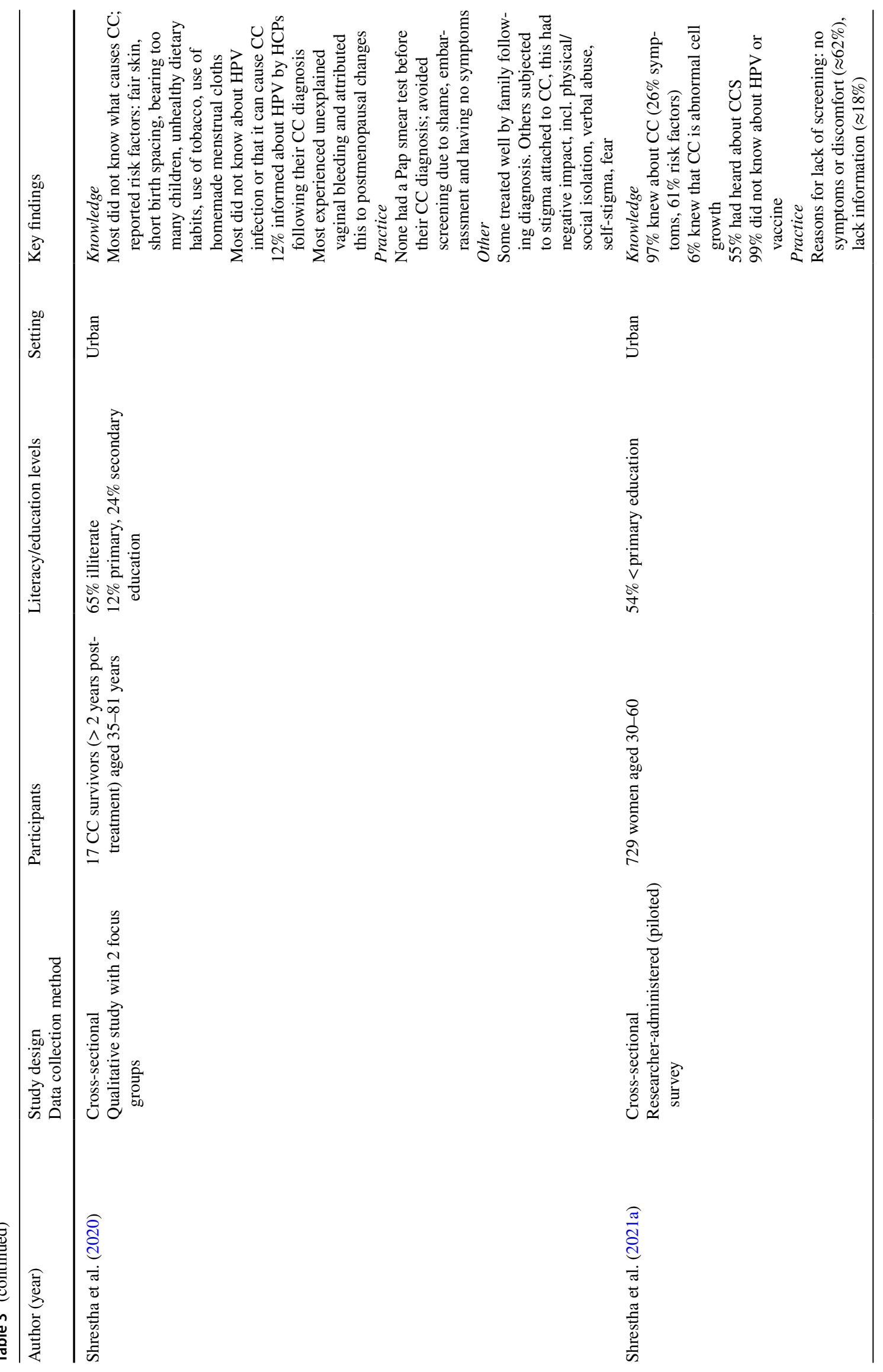




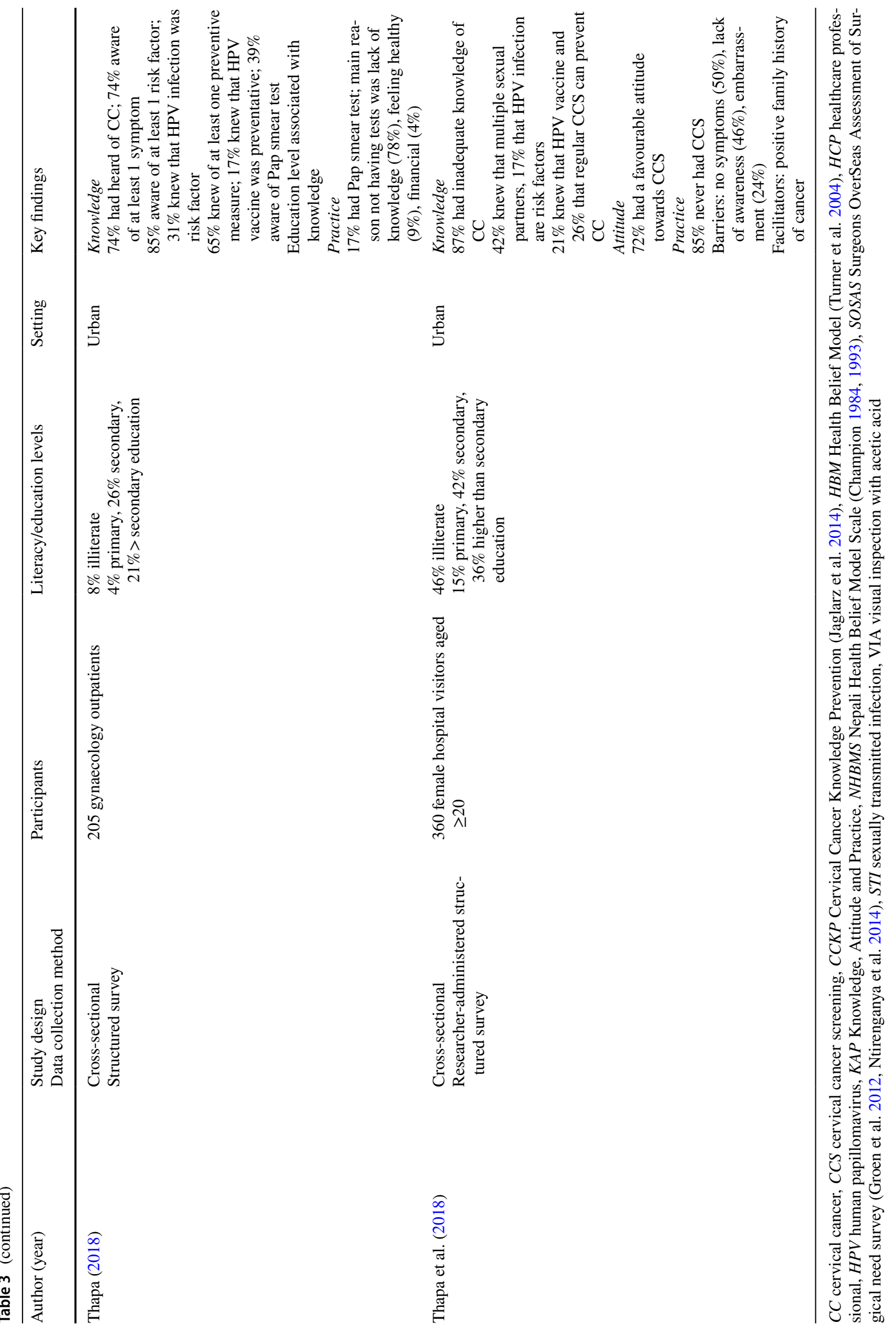


attitudes and screening practices with respect to $\mathrm{CC}$. The percentage of women who had heard of CC ranged from 6\% (Shakya et al. 2016) to 97\% (Shrestha et al. 2021a). The study with the lowest percentage was conducted in a rural area and involved 122 members of a micro-finance women's group. The study with the highest percentage took place among 729 participants recruited for a community-based intervention study to improve cervical cancer screening uptake in Pokhara Metropolitan.

Knowledge of signs and symptoms of CC varied widely among studies (Khadka et al. 2017; Shakya et al. 2016; Shah et al. 2010; Shrestha 2014; Shrestha et al. 2020; Shrestha et al. 2021a; Thapa 2018; Thapa et al. 2018). Although almost all women in the study by Shrestha et al. (2021a) had heard about CC, only $26 \%$ were aware of symptoms and $6 \%$ knew that CC is an abnormal cell growth. Shakya et al. (2016) found that $61 \%$ lacked knowledge of symptoms, and of those who mentioned symptoms, $25 \%$ reported incorrect information. Another study reported that respectively 55\% and $61 \%$ of women knew that abnormal vaginal discharge and bleeding are CC symptoms (Shrestha 2014). Khadka et al. (2017) found that $55 \%$ were aware of warning signs and symptoms of CC, and of those, $97 \%$ believed it to be a fatal disease.

The main sources for CC knowledge were media (i.e. television), social media, friends and family, and government clinics (Bhatta et al. 2020, Poudel and Sumi 2019; Thapa 2018; Pandey and Karmacharya 2017; Sherpa 2007).

Increased knowledge of CC was associated with living in a suburban area (Johnson et al. 2014), higher education levels, certain occupations and monthly household incomes (Khadka et al. 2017). Mothers of female students had better knowledge than mothers of male students (Poudel and Sumi 2019). A study of 150 female undergraduate students, however, found no significant association between knowledge and selected variables, including age, family income and smoking (Rachana and Giri 2019).

Knowledge of cervical cancer risk factors Eleven studies reported on knowledge of CC risk factors (Darj et al. 2019; Joy et al. 2011, Khadka et al. 2017; Poudel and Sumi 2019; Shah et al. 2010; Shakya et al. 2016; Shrestha 2014; Shrestha 2017; Shrestha et al. 2021a, b; Thapa 2018; Thapa et al. 2018). Shrestha et al. (2021a) found that of the 729 women interviewed from an urban area, $61 \%$ correctly identified risk factors for CC. Thapa (2018) found that of 205 women living in an urban area, $85 \%$ were aware of at least one risk factor for CC. Khadka et al. (2017) interviewed 600 rural women, and $37 \%$ were aware of risk factors. Most women cited early age of sexual debut, multiple sexual partners and poor personal hygiene. In contrast, Shrestha (2017) found that of 2529 rural women, just 6\% had knowledge of risk factors. Studies also showed that misconceptions around
$\mathrm{CC}$ and its symptoms still persist among women in Nepal. Shakya et al. (2016) reported that in a group of 122 women aged 18 to 68 years, $96 \%$ mentioned one or more CC risk factors but $13 \%$ cited incorrect information. A qualitative study in $17 \mathrm{CC}$ survivors showed that most were unaware of what causes CC, and some reported incorrect risk factors such as having fair skin or using homemade menstrual cloths (Shrestha et al. 2020). Darj et al. (2019) found that misconceptions about risk factors persisted even after participation in a $\mathrm{CC}$ awareness programme.

Knowledge and practice of cervical cancer screening With the exception of four studies (Bhatta et al. 2020; Johnson et al. 2014; Joy et al. 2011; Sherpa et al. 2020), all assessed knowledge and/or attitudes towards cervical cancer screening (CCS) and screening practice. CCS knowledge varied widely. Shakya et al. (2016) found that all women $(n=122)$ who had participated in community-based educational meetings lacked knowledge of Pap smear tests. In contrast, Pandey and Karmacharya (2017) found in a researcher-administered survey among 180 women that $81 \%$ had heard of CCS, mainly (57\%) through information from HCPs. Both studies took place in rural areas.

The number of women who had heard of the Pap smear test ranged from 7\% (Khadka et al. 2017) to 69\% (Shrestha and Dhakal 2017). Some studies found that women had adequate CCS knowledge, for example that CCS is a way of preventing cancer by detecting cancers or abnormalities that could lead to cancer. The lowest level (11\%) was found by Baral et al. (2020) in a study of 170 hospital outpatients and visitors from an urban area. A study of 96 gynaecological outpatients found that the only factor significantly associated with level of CCS knowledge was education (Shrestha and Dhakal 2017), which was confirmed in two other studies (Khadka et al. 2017; Thapa 2018).

Only one study reported on knowledge of visual inspection with acetic acid (VIA) for CCS. Sherpa et al. conducted a researcher-administered survey among 102 high school or secondary school teachers aged between 20 and 56 years, and around one in five (21\%) had heard of VIA.

Few women had experience with CCS, with percentages of women who (ever) had CCS ranging from $2 \%$ (Shah et al. 2010) to $47 \%$ (Andersen et al. 2020). The most commonly reported reasons for not having CCS were lack of information about $\mathrm{CC}$ and screening and lack of symptoms or discomfort. Other reasons included illiteracy, lack of finance, shame or embarrassment, living in rural or low-income areas, concerns regarding side effects or that the procedure is painful, and fear that screening would result in positive results or a cancer diagnosis (Darj et al. 2019; Maharjan et al. 2020; Poudel and Sumi 2019; Ranjit et al. 2016; Satyal 2013; Sherpa 2007; Sherpa et al. 2020; Shrestha et al. 2013; Shrestha 2014; Shrestha 2017; Shrestha and Dhakal 2017; 
Shrestha et al. 2020; Shrestha et al. 2021a; Thapa 2018; Thapa et al. 2018). Factors associated with higher uptake of CCS included older age, higher education, awareness about costs, knowledge of the availability of CCS services, urban residency, education programmes or a positive family history of cancer (Darj et al. 2019; Ghimire and Pathak 2020; Ranabhat et al. 2014; Thapa 2018; Thapa et al. 2018).

Eight studies reported on attitudes towards CCS (Baral et al. 2020; Ranabhat et al. 2014; Shah et al. 2010; Shakya et al. 2016; Shrestha et al. 2013; Shrestha 2014; Shrestha and Dhakal 2017; Thapa et al. 2018). Positive attitudes towards CCS among women ranged from 10\% (Shrestha and Dhakal 2017) to $72 \%$ (Thapa et al. 2018). Factors associated with favourable attitudes identified by Baral et al. (2020) were ethnicity, employment and marital status. Shah et al. (2010) reported that positive attitudes towards CCS were related to higher knowledge of risk factors and screening modalities. Shrestha (2014) found that a positive attitude towards CCS was associated with a higher level of education and adequate knowledge of CCS. Only one study found that illiterate and married women had higher favourable attitudes towards CCS (Thapa et al. 2018). Shakya et al. (2016) showed that community-based health education had a positive influence on the attitude towards CCS among women in a rural area of Nepal. All participants were in favour of CCS, while before the educational session, only $16 \%$ were willing to have CCS, $59 \%$ were unsure, and 25\% refused CCS because they believed they were not at risk for CC.

The qualitative studies in this review provided more indepth insights into women's experiences and beliefs regarding CCS. Andersen et al. (2020) examined the barriers to and facilitators of CCS participation through focus groups and interviews with 44 women aged between 30 and 60 years. The main barriers were lack of permission from their husbands, fear of social exclusion and gossip, poverty and transportation costs. The main facilitators were autonomy of women with regard to making their own health-related decisions, public awareness campaigns to reduce stigma around $\mathrm{CC}$ and CCS, and screening being free of charge.

Sex and sexual health are sensitive topics in Nepali women, and many women will not have visited a gynaecologist or only for specific reasons, such as pregnancy (Menger et al. 2015). Avoiding CCS because of shame and embarrassment was stated by $17 \mathrm{CC}$ survivors who had completed 2 years of treatment and participated in focus groups. None of the women ever had any type of CCS before they were diagnosed with $\mathrm{CC}$, and some were reluctant to undergo treatment after their diagnosis or endured social stigma in the form of physical isolation and verbal abuse. However, because of their own experiences with $\mathrm{CC}$, they realized the importance of screening methods for early detection and treatment.
A preference for female HCPs to perform the CCS and consultations was stated by women in the study by Andersen et al. (2020). Study participants also highlighted that trust and confidentiality, and skills and training were important to facilitate CCS uptake. Darj et al. (2019) reported similar findings in a series of focus groups with 72 gynaecology outpatients aged between 25 and 60 years. All women were married, as gynaecological examinations were not performed for unmarried women. They believed that HCP negligence or incompetence would cause their health to deteriorate and cause complications and they were hesitant about attending clinics.

Knowledge and attitudes towards human papillomavirus infection and vaccine The human papillomavirus (HPV) is a major cause of the main types of cervical cancer. Sixteen studies assessed women's knowledge of HPV infection or vaccine (Baral et al. 2020; Bhatta et al. 2020; Johnson et al. 2014; Joy et al. 2011; Khadka et al. 2017; Poudel and Sumi 2019; Rachana and Giri 2019; Shah et al. 2010; Shakya et al. 2016; Sherpa et al. 2020; Shrestha 2014; Shrestha and Dhakal 2017; Shrestha et al. 2020; Shrestha et al. 2021a; Thapa et al. 2018; Thapa 2018). The percentage of women who had heard of HPV ranged from 0\% (Shakya et al. 2016) to 53\% (Joy et al. 2011). Women who knew about the link between HPV infection and CC ranged from less than 1\% (Sherpa et al. 2020) to 39\% (Shrestha 2014).

Knowledge about the sexual transmission of HPV was mentioned in two studies. In a study by Khadka et al. (2017) among 600 women aged 15 to 49 years, only $5 \%$ had heard of HPV, but the majority ( $80 \%)$ knew that this infection is sexually transmitted. Joy et al. (2011) reported the findings of a self-administered survey among 480 female students and noted that $53 \%$ had heard of HPV, of whom $51 \%$ knew that the infection can be transmitted through (multiple) sexual partners, and $43 \%$ that condom use does not prevent transmission. Three other studies also cited multiple sexual partners as a common risk factor for CC (Khadka et al. 2017; Shakya et al. 2016; Thapa et al. 2018).

Only one study examined factors associated with HPV knowledge, and found that lower knowledge levels were associated with education level (illiteracy, informal education), type of occupation (unskilled jobs) and lower monthly household income (Khadka et al. 2017).

Ten studies reported on awareness of or attitudes towards the HPV vaccine (Baral et al. 2020; Bhatta et al. 2020; Johnson et al. 2014; Khadka et al. 2017; Poudel and Sumi 2019; Rachana and Giri 2019; Sherpa et al. 2020; Shrestha et al. 2021a; Thapa 2018; Thapa et al. 2018). Knowledge ranged from 3\% (Khadka et al. 2017) to 14\% (Bhatta et al. 2020), of which 10\% (Baral et al. 2020) to 38\% (Rachana and Giri 2019) of women knew that having the vaccine can prevent CC. Shrestha and Dhakal (2017) reported that $12 \%$ 
mistakenly believed women who had the HPV vaccine did not need CCS. Two studies noted that although few women had heard of the HPV vaccine (up to 14\%), the majority (over 90\%) would vaccinate themselves or their children if the vaccination were provided at no cost (Bhatta et al. 2020; Khadka et al. 2017). Barriers to vaccine uptake were low awareness, financial concerns and concerns regarding side effects. Older age and higher income were associated with willingness to accept the HPV vaccine (Bhatta et al. 2020).

\section{Discussion}

$\mathrm{BC}$ and $\mathrm{CC}$ are the two most common cancers in women in Nepal. Not only do they result in significant morbidity and mortality, but in 2012 it was estimated that the total lost productivity in Nepal resulting from female cancers was $\$ 121$ million (Roy Chowdhury and Bohara 2020). This is the first review on knowledge, attitudes and screening practices for BC and CC among women in Nepal. The study found that for both cancers, levels of knowledge including early warning signs, symptoms and risk factors were generally poor. Furthermore, screening practices were inadequate and often resulted from lack of knowledge about the disease or screening routines. Common reasons for lack of screening included a lack of belief in personal need for screening, fear of finding abnormalities and concerns regarding social stigma. Higher rates of screening were seen in women with higher education levels, higher knowledge levels of both cancers and participation in awareness campaigns. Positive attitudes towards CCS were associated with higher levels of education and more knowledge of CCS and risk factors for CC; however, few studies reported on attitudes towards BC and CC.

Our results regarding $\mathrm{BC}$ and $\mathrm{CC}$ screening behaviours align with findings from other studies. A meta-analysis conducted by Kassie et al. (2020) estimated that the uptake of CCS among women in Ethiopia was 8\% and knowledge of $\mathrm{CC}$ was significantly associated with the utilisation of CCS. A review of the uptake of $\mathrm{BC}$ screening in low-resource countries found that utilisation of BC screening in Asian countries was 19\% (Mahumud et al. 2020). Factors increasing uptake of BC screening were higher education levels, older age at first birth (i.e. 25 years or older), female-headed households, access to media communication and urban residency. Another systematic review found that screening practices for both cancers were increased in women with more opportunities for knowledge acquisition, such as higher education levels, urban residency and employment outside the home (Islam et al. 2017). This highlights the importance of ensuring that interventions to increase knowledge include women with fewer opportunities for knowledge acquisition.
Multiple articles have found similar barriers to screening as those highlighted in this scoping review. A study in Indonesia reported barriers to CCS including dislike of pelvic exams, discomfort of screening conducted by male HCPs, financial concerns, anxiety regarding abnormal results and the misconception that there is no need for screening when asymptomatic (Spagnoletti et al. 2019). Pierz et al. (2020) noted that in sub-Saharan Africa, barriers to CCS included lack of knowledge about BC and CC, lack of support from husbands, and the stigmatisation of the utilisation of CCS and $\mathrm{BC}$ screening services. Another systematic review evaluating the uptake of CCS in LMICs found barriers to be lack of knowledge/awareness, embarrassment and lack of familial support (Devarapalli et al. 2019). Islam et al. (2017) conducted a systematic review and concluded that key barriers to both BC and CC screening in LMICs were lack of knowledge of both cancers and a poor understanding of the role of screening. Taken together, these results suggest that poor knowledge and awareness of both cancers, stigmatisation from family and the community, lack of affordable healthcare and embarrassment of intimate examinations all contribute to poor $\mathrm{BC}$ and $\mathrm{CC}$ screening practices.

Our review found that, although knowledge of the HPV vaccine was low, on the whole, women had a positive attitude towards the HPV vaccine, which was also reported previously. A systematic review about attitudes towards the HPV vaccine in South-East Asia by Kristina et al. (2019) reported low knowledge levels of the vaccine; nevertheless, individuals were willing to receive it. Spagnoletti et al. (2019) found that although most participants had no knowledge of the HPV vaccine or the causal link between HPV and $\mathrm{CC}$, most were still willing to vaccinate their children against HPV.

\section{Future interventions for cervical cancer}

The World Health Organization (WHO) have called for the elimination of CC by the end of the century (Gravitt et al. 2021; WHO 2020). The targets to achieve this include implementing HPV vaccination and increasing access to cervical screening and management interventions (Gravitt et al. 2021; WHO 2020, Gultekin et al. 2020). Although countries with a higher incidence of $\mathrm{CC}$ will likely take longer to achieve these goals, substantial gains can be made in the short term through implementation of recommended actions (Gultekin et al. 2020). A demand for screening and vaccines from the public through awareness campaigns are key in ensuring the WHO targets will be met. One way to do this is through education programmes, working on the premise that low knowledge and awareness are primary barriers to screening uptake. One of the studies in our review found that the number of women willing to participate in CCS rose from $16 \%$ to $100 \%$ following an educational meeting about 
CC and CCS (Shakya et al. 2016). Moreover, the 122 study participants recruited an additional 222 peers for screening. This shows that community-based education programmes in Nepal can improve willingness for CCS and that women's social circles play a role in promoting CCS. Lott et al. (2020) reviewed interventions aimed to increase the uptake of CCS in sub-Saharan Africa. They concluded that educational interventions work better when peer health educators or community health workers (CHWs) are used, as educators are known to the participants.

O'Donovan et al. (2019) reviewed the literature surrounding the role of CHWs for CCS in LMICs, reporting that not only do CHWs play important roles in community-based education and CCS awareness, but they can also assist/conduct CCS and follow women up throughout the screening process. The first study investigating the effect of a community-based intervention by female community health volunteers (FCHVs) on CCS uptake among women in Nepal is currently underway, with last endpoint assessments for August 2021 (Shrestha et al. 2021b). CHWs play an important role in understanding, often nuanced, cultural barriers within communities; this study will therefore provide important insights into the potential roles that $\mathrm{CHW} / \mathrm{FCHV}$ can have in future CCS programmes in Nepal. However, including CHWs in screening programmes for $\mathrm{BC}$ and $\mathrm{CC}$ does not come without challenges; some women reported that they did not want people they knew to conduct these intimate examinations; there are also reports of errors in data collected by CHWs, and concerns regarding the sustainability of these programmes, as high turnover of CHWs has been documented (O'Donovan et al. 2019, 2020).

In 2012, WHO launched a mobile health (mHealth) initiative to combat NCDs. Mobile phone applications and text messaging services are used to improve disease protection, management and control. mHealth could improve the control of CC in LMICs (Denny et al. 2017). Zhang et al. (2021) found through a systematic review that mHealth, especially telephone reminders/messages, lead to increased uptake of Pap smear tests. Further research, however, needs to be done to determine whether mHealth can be used to increase knowledge of CC. Future trials should look into the role of mHealth in increasing awareness and screening practices for BC and CC in Nepal.

\section{Future interventions for breast cancer}

WHO have created the Global Breast Cancer Initiative, with the primary goal of reducing global $\mathrm{BC}$ mortality through increased access to early diagnosis and prompt $\mathrm{BC}$ treatment (Anderson et al. 2021). In LMICs, women with BC often present at a later stage of disease, leading to increased rates of morbidity and mortality in comparison to HICs (Anderson et al. 2021). It is therefore important that women in
LMICs are aware of $\mathrm{BC}$ and the importance of screening to reduce the number of women presenting with late-stage $\mathrm{BC}$. Mammography is a non-invasive screening method for BC, and there is evidence that it reduces mortality if women aged 50-69 are screened every 2 years (Siu 2016). Mammography, however, is expensive and therefore not recommended by WHO for populations in LMICs (Ngan et al. 2020; WHO 2014). BSE and CBE are low-cost $B C$ screening alternatives in these countries (WHO 2014). An education programme with schoolgirls in Nepal increased mean BSE knowledge scores from 33\% to 85\% (Sapkota et al. 2016). It is important, however, that increases seen in knowledge levels translate to increased BSE practices.

CHWs can play a number of important roles in early BC detection initiatives in LMICs (Hand et al. 2021). These roles include raising awareness, taking histories, performing CBE, making referrals and following up patients (O'Donovan et al. 2020). A systematic review published in 2020 looking at CBE in LMICs found no reduction in breast cancer mortality with CBE compared to no screening (Ngan et al. 2020). Conversely, Mittra et al. (2021) conducted a large study on the benefits of CBE with 151,538 women in Mumbai, India over 20 years. Women in the screening arm $(n=75,630)$ had CBE conducted by trained female primary healthcare workers every 2 years. Not only was BC detected at an earlier stage in the screening group than in the control, but there was a significant reduction of nearly $30 \%$ in mortality in women aged 50 years or older. It was concluded that CBE should be considered in LMICs as a method of screening for BC. It would therefore be beneficial for future research to be conducted on the use of $\mathrm{CBE}$ as a screening method in Nepal.

\section{Strengths and limitations}

The key strengths of this review are that it is the first of its kind, it focused on the two most common cancers in women in Nepal, and included large numbers of women and recently published studies, as $24 \%$ were published very recently $(2020,2021)$. Women were included from a wide range of ages and backgrounds, and from both rural and urban areas. A final strength of this review is that it included both quantitative and qualitative studies. Three recently published qualitative articles provide important insights into reasons for low CC awareness, ultimately informing target areas for future interventions.

Several limitations need to be acknowledged. Firstly, as this was a scoping review with the aim of identifying gaps in knowledge, articles included were not appraised. Additionally, eight of the included studies used a convenience sampling technique, and thus it is unknown whether there is any bias as a result. Another eight studies sampled women from hospital settings, including gynaecological in- and 
outpatient units. These women have access to healthcare and may, therefore, be more health-literate. Another limitation is that this review focused on articles in English, so it is possible that reports in Nepali could have been overlooked. Finally, the majority of studies in this review focused on CC; future research should be conducted on knowledge, attitudes and screening practices for $\mathrm{BC}$.

\section{Conclusion}

This study has shown that levels of knowledge and screening practices for BC and CC are low among women in Nepal. This results from socio-cultural, geographical and financial barriers. Screening practices were higher in women with better knowledge and awareness. It was also shown that attitudes towards BC and CC screening and towards the HPV vaccine were generally positive, especially in women with high levels of knowledge or after educational interventions. This is promising for future screening programmes in Nepal. Reducing the burden of $\mathrm{BC}$ and $\mathrm{CC}$ in Nepal will require earlier detection of both cancers through accessible screening programmes. Implementation of the HPV vaccine in line with the WHO targets will further help by reducing the incidence of CC. Finally, widespread financial and geographical barriers to accessing healthcare in Nepal must be addressed. Women need more than just knowledge about cancer; they need access to treatment. Future studies should focus on knowledge, attitudes and screening practices regarding BC and the use of CHWs for BC in Nepal, and explore the use of mHealth to increase cancer awareness among the public.

Supplementary Information The online version contains supplementary material available at https://doi.org/10.1007/s10389-021-01688-7.

\begin{abstract}
Authors' contributions CR contributed to search strategy development, conducted the searches and abstract screening, full-text screening, the data abstraction and data synthesis, and co-wrote the paper. $\mathrm{HH}$ supervised the project, advised on search strategy and data synthesis, contributed to abstract screening and full-text screening, co-wrote the paper, completed the formatting, and commented on all stages of the manuscript. SB advised on the data abstraction, contributed to data abstraction, and commented on multiple stages of the manuscript.
\end{abstract}

Availability of data and material Not applicable.

Code availability Not applicable.

\section{Declarations}

Conflicts of interest/competing interests The authors have no relevant financial or non-financial interests to disclose.

Ethics approval This is a scoping review. Ethical approval for this research was not required.
Consent to participate This is a scoping review. Consent to participate was not required.

Consent for publication Not applicable.

Open Access This article is licensed under a Creative Commons Attribution 4.0 International License, which permits use, sharing, adaptation, distribution and reproduction in any medium or format, as long as you give appropriate credit to the original author(s) and the source, provide a link to the Creative Commons licence, and indicate if changes were made. The images or other third party material in this article are included in the article's Creative Commons licence, unless indicated otherwise in a credit line to the material. If material is not included in the article's Creative Commons licence and your intended use is not permitted by statutory regulation or exceeds the permitted use, you will need to obtain permission directly from the copyright holder. To view a copy of this licence, visit http://creativecommons.org/licenses/by/4.0/.

\section{References}

Andersen J, Shrestha AD, Gyawali B, Neupane D, Kallestrup P (2020) Barriers and facilitators to cervical cancer screening uptake among women in Nepal: a qualitative study. Women Heal 60:112. https://doi.org/10.1080/03630242.2020.1781742

Anderson BO, Ilbawi AM, Fidarova E, Weiderpass E, Stevens L, Abdel-Wahab M et al (2021) The global breast Cancer initiative: a strategic collaboration to strengthen health care for non-communicable diseases. Lancet Oncol 2045:70-72. http://www.ncbi. nlm.nih.gov/pubmed/33691141

Baral P, Pokharel J, Gachhadar R (2020) Awareness and attitude regarding cervical cancer screening among reproductive age women. J Nepal Heal Res Counc 18:529-534

Bhandari PM, Thapa K, Dhakal S, Bhochhibhoya S, Deuja R, Acharya $P$ et al (2016) Breast cancer literacy among higher secondary students: results from a cross-sectional study in Western Nepal. BMC Cancer 16:1-9. https://doi.org/10.1186/s12885-016-2166-8

Bhandari D, Shibanuma A, Kiriya J, Hirachan S, Ong KIC, Jimba M (2021) Factors associated with breast cancer screening intention in Kathmandu Valley, Nepal. PLoS One 16:e0245856. https://doi. org/10.1371/journal.pone.0245856

Bhatt VR, Wetz RV, Shrestha R, Shrestha B, Shah N, Sayami P et al (2011) Breast cancer knowledge, attitudes and practices among Nepalese women. Eur J Cancer Care 20:810-817

Bhatta MP, Johnson DC, Lama M, Maharjan B, Lhaki P, Shrestha S (2020) Cervical cancer and human papillomavirus vaccine awareness among married Bhutanese refugee and Nepali women in eastern Nepal. J Community Health 45:516-525. https://doi.org/10. 1007/s10900-019-00770-2

Brand NR, Qu LG, Chao A, Ilbawi AM (2019) Delays and barriers to cancer care in low- and middle-income countries: a systematic review. Oncologist 24:e1371-e1380. https://doi.org/10.1634/ theoncologist.2019-0057

Braun CM, Itano JK (2001) Cancer care in Nepal. Cancer Nurs 24:137-142

Bray F, Jemal A, Grey N, Ferlay J, Forman D (2012) Global cancer transitions according to the human development index (20082030): a population-based study. Lancet Oncol 13:790-801

Champion VL (1984) Instrument development for health belief model constructs. Adv Nurs Sci 6:73-85

Champion LA (1993) Instrument refinement for breast cancer screening behaviors. Nurs Res 42:139-143 
Darj E, Chalise P, Shakya S (2019) Barriers and facilitators to cervical cancer screening in Nepal: a qualitative study. Sex Reprod Healthc 20:20-26. https://doi.org/10.1016/j.srhc.2019.02.001

Denny L, de Sanjose S, Mutebi M, Anderson BO, Kim J, Jeronimo J et al (2017) Interventions to close the divide for women with breast and cervical cancer between low-income and middleincome countries and high-income countries. Lancet 389:861870. https://doi.org/10.1016/S0140-6736(16)31795-0

Devarapalli P, Labani S, Nagarjuna N, Panchal P (2019) Barriers affecting uptake of cervical cancer screening in low- and middle-income countries: a systematic review. Indian J Cancer 55:318-326

Ghimire P, Sapkota VP, Poudyal AK (2019) Factors associated with enrolment of households in Nepal's national health insurance program. Int J Heal Policy Manag 8:636-645. https://doi.org/10. 15171/ijhpm.2019.54

Ghimire B, Pathak P (2020) Determinants of uptake of cervical cancer screening among women attending tertiary level hospital. J Nepal Health Res Council 18:649-654. https://doi.org/10.33314/jnhrc. v18i4.2848

Ginsburg O, Bray F, Coleman MP, Vanderpuye V, Eniu A, Kotha SR et al (2017) The global burden of women's cancers: a grand challenge in global health. Lancet 389:847-860

Gravitt PE, Silver MI, Hussey HM, Arrossi S, Huchko M, Jeronimo J et al (2021) Achieving equity in cervical cancer screening in lowand middle-income countries (LMICs): strengthening health systems using a systems thinking approach. Prev Med 144:106322. https://doi.org/10.1016/j.ypmed.2020.106322

Groen RS, Samai M, Stewart KA, Cassidy LD, Kamara TB, Yambasu SE et al (2012) Untreated surgical conditions in Sierra Leone: a cluster randomized, cross-sectional, countrywide survey. Lancet 380:1082-1087

Gultekin M, Ramirez PT, Broutet N, Hutubessy R (2020) World Health Organization call for action to eliminate cervical cancer globally. Int J Gynecol Cancer 30:426-427. https://doi.org/10.1136/ ijgc-2020-001285

Gupta S, Ghimire P, Shrestha S, Ranjit A, Kingham TP, Groen RS et al (2015) Untreated breast masses: a cross-sectional countrywide survey of Nepal. Surg 158:55-57. https://doi.org/10.1016/j.surg. 2014.10.002

Gyawali B, Sharma S, Shilpakar R, Dulal S, Pariyar J, Booth CM et al (2020) Overview of delivery of cancer care in Nepal: current status and future priorities. JCO Glob Oncol 6:1211-1217. https:// doi.org/10.1200/GO.20.00287

Gyenwali D, Pariyar J, Onta SR (2013) Factors associated with late diagnosis of cervical cancer in Nepal. Asian Pacific J Cancer Prev 14:4373-4377

Hand T, Rosseau NA, Stiles CE, Sheih T, Ghandakly E, Oluwasanu M et al (2021) The global role, impact, and limitations of community health workers (CHWs) in breast cancer screening: a scoping review and recommendations to promote health equity for all. Glob Health Action 14:1883336. https://doi.org/10.1080/16549 716.2021 .1883336

Heer E, Harper A, Escandor N, Sung H, McCormack V, Fidler-Benaoudia MM (2020) Global burden and trends in premenopausal and postmenopausal breast cancer: a population-based study. Lancet Glob Health 8:e1027-e1037. https://doi.org/10.1016/S2214109X(20)30215-1

Islam RM, Billah B, Hossain N, Oldroyd J (2017) Barriers to cervical cancer and breast cancer screening uptake in low-income and middle-income countries : a systematic review. Asian Pac J Cancer Prev 18:1751-1763

Jaglarz K, Tomaszewski KA, Kamzol W, Puskulluoglu M (2014) Creating and field-testing the questionnaire for the assessment of knowledge about cervical cancer and its prevention among schoolgirls and female students. J Gynecol Oncol 25:81-89
Johnson DC, Bhatta MP, Gurung S, Aryal S, Lhaki P, Shrestha S (2014) Knowledge and awareness of human papillomavirus (HPV), cervical cancer and HPV vaccine among women in two distinct Nepali communities. Asian Pacific J Cancer Prev 15:8287-8293

Joy T, Sathian B, Bhattarai C, Chacko J (2011) Awareness of cervix cancer risk factors in educated youth: a cross-sectional, questionnaire based survey in India, Nepal, and Sri Lanka. Asian Pacific J Cancer Prev 12:1707-1712

Kafle P, Panth A (2017) Cervical cancer screening practices and barriers among women in Nepal. Am J Cancer Prevention 5:31-33. https://doi.org/10.12691/ajcp-5-2-4

Kassie AM, Abate BB, Kassaw MW, Aragie TG, Geleta BA, Shiferaw WS (2020) Impact of knowledge and attitude on the utilization rate of cervical cancer screening tests among Ethiopian women: a systematic review and meta-analysis. PLoS One 15. https://doi. org/10.1371/journal.pone.0239927

Khadka K, Shah SK, Ts S, Mathias J, Upadhayay A (2017) Knowledge and awareness about cervical cancer screening and HPV vaccine among females aged 15-49 years in Rukum district of Nepal. Am J Cancer Prev 5:10-16

Khatiwoda SR, Dhungana RR, Sapkota VP, Singh S (2019) Estimating the direct cost of cancer in Nepal: a cross-sectional study in a tertiary cancer hospital. Front Public Health 7:160. https:// doi.org/10.3389/fpubh.2019.00160

Koirala R, Gurung N, Dhakal S, Karki S (2021) Role of cancer literacy in cancer screening behaviour among adults of Kaski district. Nepal PLoS One 16(7):e0254565. https://doi.org/10.1371/ journal.pone. 0254565

Kristina SA, Putu N, Linda A (2019) Knowledge, attitudes and barriers towards human papillomavirus (HPV) vaccination in developing economies countries of South-East Asia region: a systematic review. Sys Rev Pharm 10:81-86

Lott BE, Trejo MJ, Baum C, Mcclelland DJ, Adsul P, Madhivanan P et al (2020) Interventions to increase uptake of cervical screening in sub-Saharan Africa: a scoping review using the integrated behavioral model. BMC Public Health 20:1-18

Maharjan M, Thapa N, Panthi D, Maharjan N, Petrini MA, Jiong Y (2020) Health beliefs and practices regarding cervical cancer screening among women in Nepal: a descriptive cross-sectional study. Nurs Health Sci 22:1084-1093

Mahumud RA, Gow J, Keramat SA, March S, Dunn J, Alam K et al (2020) Distribution and predictors associated with the use of breast cancer screening services among women in 14 lowresource countries. BMC Public Health 20:11-15

Menger LM, Kaufman MR, Harman JJ, Tsang SW, Shrestha DK (2015) Unveiling the silence: Women's sexual health and experiences in Nepal. Cult Health Sex 17:359-373. https://doi.org/ 10.1080/13691058.2014.937462

Mishra SR, Khanal P, Karki DK, Kallestrup P, Enemark U (2015) National health insurance policy in Nepal: challenges for implementation. Glob Health Action 8:28763. https://doi.org/10. 3402/gha.v8.28763

Mittra I, Mishra GA, Dikshit RP, Gupta S, Kulkarni VY, Shaikh HKA et al (2021) Effect of screening by clinical breast examination on breast cancer incidence and mortality after 20 years: prospective, cluster randomised controlled trial in Mumbai. BMJ 1-9. https://doi.org/10.1136/bmj.n256

Musa J, Achenbach CJ, O'Dwyer LC, Evans CT, McHugh M, Hou L, Simon MA, Murphy RL, Jordan N (2017) Effect of cervical cancer education and provider recommendation for screening on screening rates: a systematic review and meta-analysis. PLoS One 12:e0183924

Narasingrao SS, Pahari S, Panta S (2013) Knowledge and attitude on breast cancer among mothers residing in Tanahu. Nepal Int J Nurs Educ 5:127 
Ngan TT, Nguyen NTQ, Van MH, Donnelly M, Neill CO (2020) Effectiveness of clinical breast examination as a 'stand-alone' screening modality: an overview of systematic reviews. BMC Cancer 20:1-10

Ntirenganya F, Petroze RT, Kamara TB, Groen RS, Kushner AL, Kyamanywa $P$ et al (2014) Prevalence of breast masses and barriers to care : results from a population-based survey in Rwanda and Sierra Leone. J Surg Oncol 110:903-906

O’Donovan J, O'Donovan C, Nagraj S (2019) The role of community health workers in cervical cancer screening in low-income and middle-income countries: a systematic scoping review of the literature. BMJ Glob Health 4:e01452. https://doi.org/10.1136/ bmjgh-2019-001452

O'Donovan J, Newcomb A, Macrae MC, Vieira D, Onyilofor C (2020) Ginsburg O (2020) community health workers and early income detection of breast cancer in low- income countries: a systematic scoping review of the literature. BMJ Glob Health 5:e02466. https://doi.org/10.1136/bmjgh-2020-002466

Oldach BR, Katz ML (2014) Health literacy and cancer screening: a systematic review. Patient Educ Couns 94:149-157. https://doi. org/10.1016/j.pec.2013.10.001

Organisation for Economic Co-operation and Development (2021) OECD DAC list of ODA assistance. https://www.oecd.org/dac/ financing-sustainable-development/development-finance-stand ards/daclist.htm. Accessed 15 June 2021

Pandey RA, Karmacharya E (2017) Cervical cancer screening behavior and associated factors among women of Ugrachandi Nala, Kavre. Nepal Eur J Med Res 22:1-9

Parajuli P, Mandal G (2010) Knowledge about breast cancer and breast self-examination practices among medical, dental and BSc nursing students of BPKIHS. Health Renaiss 8:166-168. https://doi. org/10.3126/hren.v8i3.4209

Parkin DM (2008) The role of cancer registries in cancer control. Int J Clin Oncol 13:102-111

Peters MD, Godfrey CM, Khalil H, McInerney P, Parker D, Soares CB (2015a) Guidance for conducting systematic scoping reviews. Int J Evid Based Healthc 13:141-146. https://doi.org/10.1097/XEB. 0000000000000050

Peters MD, McInerney P, Baldini Soares C, Khalil H, Parker D (2015b) Methodology for JBI scoping reviews. In: Adelaide AE (ed) The Joanna Briggs Institute Reviewers' Manual. The Joanna Briggs Institute, Australia

Pierz AJ, Randall TC, Castle PE, Adedimeji A, Ingabire C, Kubwimana $\mathrm{G}$ et al (2020) A scoping review: facilitators and barriers of cervical cancer screening and early diagnosis of breast cancer in subSaharan African health settings. Gynecol Oncol Rep 33:100605. https://doi.org/10.1016/j.gore.2020.100605

Poudel K, Sumi N (2019) Analyzing awareness on risk factors, barriers and prevention of cervical cancer among pairs of Nepali high school students and their mothers. Int J Environ Res Public Health 16(22):4382. https://doi.org/10.3390/ijerph16224382

Rachana K, Giri R (2019) Knowledge regarding cervical cancer among undergraduate female students at a selected college of Lalitpur. Nepal Can Oncol Nurs J 29:184-188

Rai SK (2018) Changing Trend of Infectious Diseases in Nepal. In: Adhikari R, Thapa S (eds) Infectious Diseases and Nanomedicine III. Advances in Experimental Medicine and Biology, Vol 1052. Springer, Singapore. https://doi.org/10.1007/ 978-981-10-7572-8_3

Ranabhat S, Tiwari M, Dhungana G, Shrestha R (2014) Association of knowledge, attitude and demographic variables with cervical pap smear practice in Nepal. Asian Pacific J Cancer Prev 15:8905-8910

Ranjit A, Gupta S, Shrestha R, Kushner AL, Nwomeh BC, Groen RS (2016) Awareness and prevalence of cervical cancer screening among women in Nepal. Int J Gynecol Obstet 134:37-40
Remais JV, Zeng G, Li G, Tian L, Engelgau MM (2013) Convergence of non-communicable and infectious diseases in low- and middleincome countries. Int J Epidemiol 42:221-227

Roy Chowdhury S, Bohara AK (2020) Measuring the societal burden of cancer: a case of lost productivity in Nepal. Public Health 185:306-311. https://doi.org/10.1016/j.puhe.2020.04.028

Sathian B, Nagaraja SB, Banerjee I, Mittal A, De A, Roy B et al (2014) Awareness of breast cancer warning signs and screening methods among female residents of Pokhara Valley, Nepal. Asian Pacific J Cancer Prev 15:4723-4726

Sathian B, Asim M, Mekkodathil A, James S, Mancha A, Ghosh A (2019) Knowledge regarding breast self-examination among women in Nepal: a meta-analysis. Nepal J Epidemiol 9:761-768. https://doi.org/10.3126/nje.v9i2.24684

Sapkota D, Parajuli P, Kafle T (2016) Effectiveness of educational intervention programme on knowledge regarding breast selfexamination among higher secondary school girls of Biratnagar. Birat J Health Sci 1:13-19

Satyal K (2013) Cervical cancer screening behavior among Nepalese women. Dissertation, George Mason University. http://ezproxy. usherbrooke.ca/login?url=https://search.ebscohost.com/login. asp $x$ direct $=$ true $\& d b=r z h \& A N=109863477 \&$ site $=$ ehost-live. Accessed 10/02/2021

Sentell TL, Tsoh JY, Davis T, Davis J, Braun KL (2015) Low health literacy and cancer screening among Chinese Americans in California: a cross-sectional analysis. BMJ Open 5:1-9

Shah T, Pokharel N, Shah S, Rai M (2010) Breast and cervical cancer risk factors and screening awareness among nurses working in government sectors in Eastern region of Nepal. Government of Nepal, Nepal Health Research Council

Shakya S, Karmacharya BM, Afset JE, Bofin A, Åsvold BO, Syversen $\mathrm{U}$ et al (2016) Community-based health education has positive influence on the attitude to cervical cancer screening among women in rural Nepal. J Cancer Educ 31:547-553. https://doi. org/10.1007/s13187-015-0863-7

Sherpa A, Yadav R, Bajracharya M (2020) Awareness and knowledge of cervical cancer screening and human papilloma virus among female school teachers in Solukhumbu, Nepal. J KIST Med Coll 2:37-43

Sherpa ATL (2007) Time for an organized cervical cancer screening in Bharatpur, Nepal. Dissertation, University of Oslo. https://www. duo.uio.no/bitstream/handle/10852/30021/Ang-Thesis-Aug-282007.pdf?sequence $=3 \&$ is Allowed $=y$ Accessed 02/02/2021

Shrestha K (2012) Breast cancer knowledge and screening practice among women visited to KIST medical college. Nepal Med Coll J 14:308-311

Shrestha J, Saha R, Tripathi N (2013) Knowledge, attitude and practice regarding cervical cancer screening amongst women visiting tertiary Centre in Kathmandu. Nepal Nepal J Med Sci 2:85-90

Shrestha P (2014) Knowledge, Attitude, and practice regarding pap smear test among women in ward no. 14, Dharan. Dissertation, The Arctic University of Norway

Shrestha A (2017) Awareness of cervical cancer and screening among rural Nepalese women. J Clin Oncol. https://doi.org/10.1200/JCO. 2017.35.15_suppl.1553

Shrestha S, Dhakal P (2017) Knowledge, attitude and practice regarding cervical cancer screening among women attending a teaching hospital, Bharatpur, Chitwan. J Fam Reprod Health 11:18-23.

Shrestha S, Chhetri S, Napit J (2017) Awareness on breast selfexamination among reproductive age women. J Coll Med Sci 13:425-429

Shrestha G, Mulmi R, Phuyal P, Thakur RK, Siwakoti B (2020) Experiences of cervical cancer survivors in Chitwan, Nepal: a qualitative study. PLoS One 15:1-14. https://doi.org/10.1371/journal.pone. 0234834 
Shrestha AD, Gyawali B, Shrestha A, Shrestha S, Neupane D, Ghimire $S$ et al (2021a) Knowledge, attitude, preventive practices and utilization of cervical cancer screening among women in Nepal: a community-based cross-sectional study. Eur J Cancer Prev. https:// doi.org/10.1097/CEJ.0000000000000670

Shrestha AD, Neupane D, Ghimire S, Campbell C, Kallestrup P (2021b) Community-based intervention for cervical cancer screening uptake in a semi-urban area of Pokhara metropolitan, Nepal (COBIN-C): study protocol for a cluster- randomized controlled trial. Trials 22:1-9. https://doi.org/10.1186/s13063-021-05049-3

Siu AL (2016) Screening for breast cancer: U.S. preventive services task force recommendation statement. Ann Intern Med 164:279-296

Spagnoletti MRB, Bennett LR, Wahdi AE, Wilopo SA, Keenan CA (2019) A qualitative study of parental knowledge and perceptions of human papillomavirus and cervical cancer prevention in rural Central Java, Indonesia: understanding community readiness for prevention interventions. Asian Pacific J Cancer Prev 20:2429-2434

Stager JL (1993) The comprehensive breast cancer knowledge test: validity and reliability. J Adv Nurs 18:1133-1140

Subedi R, Dhimal M, Budukh A, Gyawali P, Jha AK (2020) Challenges and way forward for establishing population based cancer registry in Nepal. J Nepal Health Res Counc 18:544-546. https://doi.org/ 10.33314/jnhrc.v18i3.2703

Subedi R, Budukh A, Chapagain S et al (2021) Differences in cancer incidence and pattern between urban and rural Nepal: one-year experience from two population-based cancer registries. Ecancermedicalscience 15:1229. https://doi.org/10.3332/ecancer.2021. 1229

Sung H, Ferlay J, Siegel RL, Laversanne M, Soerjomataram I, Jemal A, Bray F (2021) Global Cancer statistics 2020: GLOBOCAN estimates of incidence and mortality worldwide for 36 cancers in 185 countries. CA Cancer J Clin 71:209-249. https://doi.org/10. $3322 /$ caac. 21660

Thapa M (2018) Cervical cancer awareness and practice of pap smear test among women with gynecological problems. J Nepal Med Assoc 56:654-657
Thapa N, Maharjan M, Petrini MA, Shah R, Shah S, Maharjan N et al (2018) Knowledge, attitude, practice and barriers of cervical cancer screening among women living in mid-western rural. Nepal J Gynecol Oncol 29:1-12

Torre LA, Islami F, Siegel RL, Ward EM, Jemal A (2017) Global cancer in women: burden and trends. Cancer Epidemiol Biomark Prev 26:444-457

Tricco A, Lillie E, Zarin W, O'Brien K, Colquhoun H, Levac D et al (2018) PRISMA extension for scoping reviews (PRISMA-ScR): checklist and explanation. Ann Intern Med 169:467-473

Turner LW, Hunt SB, DiBrezzo R, Jones C (2004) Design and implementation of an osteoporosis prevention program using the health belief model. Am J Health Stud 19:115-121

World Health Organization (2014) WHO position paper on mammography screening. World Health Organization, Geneva https://apps. who.int/iris/bitstream/handle/10665/137339/9789241507936_ eng.pdf; sequence $=1$ Accessed 24/03/2021

World Health Organization (2017) Regional Office for South-East Asia. Health financing profile 2017: Nepal. https://apps.who.int/ iris/handle/10665/259643. Accessed 15 Oct 2020

World Health Organization (2020) Global strategy to accelerate the elimination of cervical cancer as a public health problem. World Health Organization, Geneva

Zhang D, Advani S, Waller J, Cupertino A, Hurtado-de-Mendoza A (2021) Mobile technologies and cervical cancer screening in lowand middle-income countries: a systematic review. JCO Glob Oncol 6:617-627

Publisher's note Springer Nature remains neutral with regard to jurisdictional claims in published maps and institutional affiliations. 